\title{
Nucleolar TFIIE plays a role in ribosomal biogenesis and performance
}

\author{
Tamara Phan ${ }^{1}$, Pallab Maity ${ }^{1}$, Christina Ludwig², Lisa Streit ${ }^{3}$, Jens Michaelis ${ }^{3}$, \\ Miltiadis Tsesmelis ${ }^{4}$, Karin Scharffetter-Kochanek ${ }^{1}$ and Sebastian Iben ${ }^{\circledR 1}{ }^{*}$ \\ ${ }^{1}$ Department of Dermatology and Allergic Diseases, Ulm University, Ulm, Baden-Württemberg, 89081 Germany,
${ }^{2}$ Bavarian Center for Biomolecular Mass Spectrometry, Technical University Munich, Freising, Bavaria 85354,
Germany, ${ }^{3}$ Institute of Biophysics, Ulm University, Ulm, Baden-Württemberg 89081 , Germany and ${ }^{4}$ Institute of
Physiological Chemistry, Ulm University, Ulm, Baden-Württemberg 89081, Germany
}

Received January 26, 2021; Revised September 09, 2021; Editorial Decision September 10, 2021; Accepted September 16, 2021

\begin{abstract}
Ribosome biogenesis is a highly energy-demanding process in eukaryotes which requires the concerted action of all three RNA polymerases. In RNA polymerase II transcription, the general transcription factor TFIIH is recruited by TFIIE to the initiation site of protein-coding genes. Distinct mutations in TFIIH and TFIIE give rise to the degenerative disorder trichothiodystrophy (TTD). Here, we uncovered an unexpected role of TFIIE in ribosomal RNA synthesis by RNA polymerase I. With high resolution microscopy we detected TFIIE in the nucleolus where TFIIE binds to actively transcribed rDNA. Mutations in TFIIE affects gene-occupancy of RNA polymerase I, rRNA maturation, ribosomal assembly and performance. In consequence, the elevated translational error rate with imbalanced protein synthesis and turnover results in an increase in heat-sensitive proteins. Collectively, mutations in TFIIE-due to impaired ribosomal biogenesis and translational accuracy-lead to a loss of protein homeostasis (proteostasis) which can partly explain the clinical phenotype in TTD.
\end{abstract}

\section{INTRODUCTION}

The biogenesis of ribosomes starts with the synthesis of pre-ribosomal RNA (rRNA) by RNA polymerase I. The pre-rRNA is co-transcriptionally matured, processed and assembled with ribosomal proteins (RP) to pre-ribosomal particles within the nucleolus (1). Ribosomal biogenesis requires the concerted action of all three RNA polymerases. While RNA polymerase I and III provide the rRNAs for ribosomal biogenesis $(60 \%$ of total transcription in growing yeast cells), $50 \%$ of RNA polymerase II transcription activity is devoted to the production of mRNAs coding for ribosomal proteins (2). 7500 ribosomal subunits per minute are synthesized in a growing HeLa cell, using up some 300000 ribosomal proteins (3). All RNA polymerases are dependent on unique sets of basal transcription factors that recognize the core promoter, recruit the RNA polymerases and organize the first steps of productive transcription (4-6). Some of these basal transcription factors are shared between the RNA polymerases like TBP, that decorated with class-specific associated proteins, is essential for all three RNA polymerases $(7,8)$. The DNA-repair factor TFIIH, consisting of ten subunits, is a basal transcription factor of RNA polymerase II. TFIIH melts the promoter and contributes to promoter escape of the polymerase (9). TFIIH is also essential for RNA polymerase I transcription (10) as an elongation factor $(11,12)$. Mutations in TFIIH cause the photosensitive form of the multisystem disorder trichothiodystrophy (TTD), a syndrome with delayed development, microcephaly, neurological degeneration, recurrent infections and eponymous skin and hair abnormalities. TTD is mainly attributed to a transcription syndrome $(13,14)$. However, recently discovered mutations in aminoacyl-tRNA synthetases that result in TTD may shift this classification towards a 'gene expression syndrome' referred to a disturbed protein translation at the ribosome $(15,16)$.

TFIIH mutations can also cause the premature aging disease Cockayne syndrome (CS) that resembles TTD with symptoms of developmental delay, microcephaly and neurodegeneration. Earlier TFIIH mutations have been reported to affect RNA polymerase I transcription and the processing of the pre-rRNA in cellular and mouse models of CS and TTD $(11,12)$. Interestingly, a recent study addressed cellular consequences of CS-mutations for RNA polymerase I transcription and uncovered disturbed RNA polymerase I transcription to be responsible for the generation of highly defective ribosomes. In the same report, defective ribosomes were found to display a profoundly reduced translational accuracy giving rise to a loss of pro-

\footnotetext{
${ }^{*}$ To whom correspondence should be addressed. Tel: +49 731 50057645; Fax: +49 731 50057660; Email: sebastian.iben@uni-ulm.de 
teostasis that in turn represses RNA polymerase I transcription (17). As mutations in subunits of RNA polymerase I or the basal transcription factor UBF were identified in syndromes of childhood neurodegeneration (18-20), it is tempting to speculate that a disturbed RNA polymerase I transcription might be causally involved in the neurodegeneration of CS and TTD.

A subset of TTD cases is caused by mutations in the RNA polymerase II transcription factor TFIIE, respective the $\beta$-subunit of this heterodimeric factor $(13,21)$. During the last steps of transcription initiation of RNA polymerase II, TFIIE $\beta$ binds to the preinitiation complex (PIC) and recruits TFIIE $\alpha$ and TFIIH to the initiation site. After phosphorylation of RNA polymerase II by TFIIH, TFIIE $\alpha$ is released from the PIC before DNA opening, while TFIIE $\beta$ dissociates after DNA opening (14,22).

We here hypothesize that TTD is a syndrome with a pathophysiological involvement of ribosomal biogenesis and protein homeostasis. If this is the case, TFIIE $\beta$ should be involved in these central processes as its mutation provokes the same TTD disease.

Here, we discovered an unanticipated role of TFIIE in rRNA synthesis, processing and performance. We detected TFIIE in the nucleolus and showed TFIIE binding to actively transcribed rDNA. TFIIE $\beta$-deficient TTD cells display reduced RNA polymerase I binding to the rDNA and disturbed pre-rRNA maturation. Impaired rRNA maturation subsequently leads to reduced ribosomal stability and unbalanced ribosomal composition in NP-TTD cells. As a consequence, ribosomes of TFIIE $\beta$-deficient TTD cells show increased translational inaccuracy and an imbalanced protein homeostasis

\section{MATERIALS AND METHODS}

\section{Reagents and resources}

Antibodies and oligonucleotides are given in Supplementary Tables S1 and S2.

\section{Cell culture}

Healthy WT controls were grown in DMEM (41965-039, Gibco) supplemented with $10 \%$ FBS and $1 \%$ penicillinstreptomycin. SV40-immortalized human NP-TTD fibroblasts (TTD218UT, TTD28N) were cultured in DMEM/HAM-F10 (P04-12500, PAN BioTech) in a ratio $1: 1$ supplemented with $10 \%$ FSB and $1 \%$ penicillinstreptomycin. Reconstituted cells (218UT TFIIE $\beta, 28 \mathrm{~N}$ TFIIE $\beta)$ were grown in DMEM/HAM-F10 (1:1) supplemented with $10 \%$ FBS, 1\% penicillin-streptomycin and 2 $\mu \mathrm{g} / \mathrm{ml}$ puromycin. All cells were cultured at $37^{\circ} \mathrm{C}$ and $5 \%$ $\mathrm{CO}_{2}$. For RNA polymerase I transcription inhibition, cells on culture dishes with $80 \%$ cell density were incubated with $1 \mu \mathrm{M}$ CX5461 for $4 \mathrm{~h}$.

\section{Sequence analysis of D187Y variation}

The homozygous point mutation in NP-TTD genome was verified by primers binding 100 nucleotides up- and downstream from the variation (forward: 5' GTATACTGAG TGTGTTAAGGAAATG 3'; reverse 5' AAAGCTCACC
TTCATCCAC $3^{\prime}$ ). PCR product was used for Sangersequencing and data were analyzed by using CLC Workbench 7.7.3.

\section{Reconstitution of 218 UT TFIIE $\beta$ and $28 \mathrm{~N}$ TFIIE $\beta$ cell lines}

NP-TTD cells were reconstituted with a plasmid overexpressing wild-type TFIIE $\beta-G F P . ~ 2 \times 10^{6}$ TTD cells were transfected with $3 \mu \mathrm{g}$ plasmid via electroporation using Neon $^{\top M}$ Transfection System (MPK1096, Invitrogen) with following parameters: $1100 \mathrm{~V}, 20 \mathrm{~ms}$ and $2 \times$ pulses. Plasmid transfection was verified by flow cytometry. Cells were washed in PBS and flow cytometry analysis were performed in FACS buffer (PBS including 2\% FBS). The data was analyzed with FlowJo Software.

\section{Immunofluorescence}

Cells were seeded on pölylysine covered slides for 1 day. $80 \%$ confluent cells were washed with PBS, fixed with $4 \%$ paraformaldehyde $\left(4^{\circ} \mathrm{C}\right)$ for $15 \mathrm{~min}$, washed with PBS, permeabilized with $0.3 \%$ Triton X-100/PBS and blocked at RT for $1 \mathrm{~h}$ with 5\% BSA including 10\% goat serum. Antibodies were diluted in Dako Antibody Diluent and cells were incubated with primary antibodies at $4^{\circ} \mathrm{C}$ overnight in a moist chamber. Cells were washed with PBS, incubated with secondary antibodies at RT for $1 \mathrm{~h}$ in a moist chamber, washed with PBS and incubated at RT for $1 \mathrm{~h}$ with the DNA probe SPY650-DNA (SC501, SpiroChrome). After washing with PBS, cells were embedded in Dako mounting medium. Images were taken by fluorescence microscope (Zeiss Axio Imager M1, 64 oil objective), confocal microscope (Zeiss Axio Observer Z1 confocal laser scanning microscope, 100 oil objective) and processed and quantified by using ImageJ.

\section{Super-resolution microscopy}

Super-resolution optical microscopy images were taken using a custom built dual-color 3D STED microscope (23). Therefore, $3 \times 10^{4}$ cells were seeded on glass Ibidi $\mu$-slide 8 -well glass-bottom plates and incubated o/n. Cells were subsequently fixed with EM-grade PFA and immunostaining was performed as described above. Finally, cells were mounted in 97\% 2,2' -thiodiethanol (TDE) for index matching. Antibodies used for immunofluorescence are given in Supplementary Table S1. Typically, an excitation power of $1 \mu \mathrm{W}$ and a depletion power of $1.3 \mathrm{~mW}$ and a repetition rate of $1 \mathrm{Mhz}$ were used. The STED images have a pixel size of $20 \mathrm{~nm}$ and were captured with a pixel dwell time of $300 \mu \mathrm{s}$. Images were analyzed using ImageJ 1.51f and a Gaussian Blur of $\sigma=1$ was applied. For better visualization brightness and contrast, settings were adapted for the images.

\section{Real-time qPCR standard curve analysis}

One microgram of total RNAs were reverse transcribed with Moloney murine leukemia virus Reverse Transcriptase (M170B, Promega). 100 ng cDNA and FastStart Universal SYBR Green Master (04913850001, Roche Diagnostics) were used for real-time qPCR analysis (denaturation 
at $95^{\circ} \mathrm{C}$ for $10 \mathrm{~s}$, annealing at $60-68^{\circ} \mathrm{C}$ for $30 \mathrm{~s}$, elongation at $72^{\circ} \mathrm{C}$ for $30 \mathrm{~s}$ ). A prepared standard curve of the oligonucleotide of interest with linear regression with $R^{2}$ values $>0.8$ was used for calculation of the absolute amount (ng) of the oligonucleotide of interest within 100ng total cDNA. Primers used for qPCR analysis are listed in Supplementary Table S2.

\section{Chromatin immunoprecipitation (ChIP)}

Eighty percent confluent cells were fixed with $1 \%$ formaldehyde (28908, Thermofisher Scientific) at RT for $10 \mathrm{~min}$ and $0.125 \mathrm{M}$ glycine was used to stop cross-linking reaction. Cells were washed with PBS, harvest and lysed with ChIP cell lysis buffer ( $5 \mathrm{mM}$ HEPES pH $8.0,85 \mathrm{mM} \mathrm{KCl}$, $0.5 \% \mathrm{NP}-40$ (Pierce) and 1:50 cOmplete proteinase inhibitor cocktail mix (Roche)) on ice for $10 \mathrm{~min}$. Pelleted Chromatin was sonicated in ChIP sonicate buffer (50 mM HEPES $\mathrm{pH}$ $7.9,140 \mathrm{M} \mathrm{NaCl}, 1 \mathrm{mM}$ EDTA, $1 \%$ Triton X 100, 0.1\% Nadeoxycholate, $0.1 \%$ SDS, $0.5 \mathrm{mM}$ PMSF, 1:50 cOmplete) by a Focused-ultrasonicator (Covaris M220, $1 \mathrm{ml}$ ) to yield chromatin fragments with an average size of $600 \mathrm{bp}$. For chromatin precipitation, Protein A agarose beads (20334, Pierce) or Protein A magnetic Dyna beads (10002D, Invitrogen) were used. After incubating $10 \mu \mathrm{g}$ chromatin with antibodies at $4{ }^{\circ} \mathrm{C}$ overnight in IP diluent $(0.1 \%$ SDS, $1 \%$ Triton $\mathrm{X} 100,1 \mathrm{mM}$ EDTA pH 8.0, $16.7 \mathrm{mM}$ Tris-Cl pH 8.0, 167 $\mathrm{mM} \mathrm{NaCl}, 1: 50$ cOmplete), chromatin-antibody-complexes were washed first with low salt buffer $(0.1 \%$ SDS, $1 \%$ Triton X 100, 2 mM EDTA, $20 \mathrm{mM}$ Tris-Cl, pH 8.1, $150 \mathrm{mM}$ $\mathrm{NaCl})$, then with high-salt buffer $(0.1 \%$ SDS, $1 \%$ Triton $\mathrm{X}$ 100, 2 mM EDTA, 20 mM Tris-Cl, pH 8.1, $500 \mathrm{mM} \mathrm{NaCl}$ ), with $\mathrm{LiCl}$ buffer (10 mM Tris-Cl pH 8.0, $250 \mathrm{mM} \mathrm{LiCl}, 1 \%$ NP40, 1\% Na-deoxycholic acid, 1 mM EDTA). and twice with TE buffer (10 mM Tris $\mathrm{pH} 8,1 \mathrm{mM}$ EDTA). ChIPed DNA was eluted from beads in $\mu$ ChIP elution Buffer (10 $\mathrm{mM}$ Tris-Cl $\mathrm{pH} 8,1 \mathrm{mM}$ EDTA $\mathrm{pH} 8,1 \%$ SDS, $1 \%$ proteinase $\mathrm{K}$ ) for $2 \mathrm{~h}$ at $60^{\circ} \mathrm{C}$ with $900 \mathrm{rpm}$. ChIPed DNA was purified by using QIAquick ${ }^{\circledR}$ Nucleotide Removal Kit (28306, Qiagen) according to the manufacturer's protocol. Samples were qualitative or quantitative analyzed via PCR or qPCR, respectively. For qualitative ChIP analysis, samples were loaded on $1 \%$ agarose gel and visualized by using Ged-Doc-It Imager (UVP). For sequential ChIP analysis (Re-ChIP), samples were released after the first round of precipitation by incubation in $10 \mathrm{mM}$ DTT for $30 \mathrm{~min}$ at $37^{\circ} \mathrm{C}$ at $500 \mathrm{rpm}$ and incubated with the respective other antibody for the second round of precipitation. Primers and antibodies used for ChIP analysis are given in Supplementary Tables S1 and S2.

\section{Nuclear Run-on Assay}

$5 \times 10^{7}$ cells were grown on $15 \mathrm{~cm}$ culture dishes until $80 \%$ cell density, washed with cold PBS and collected in a $50 \mathrm{ml}$ falcon tube by scraping and centrifuging for 5 min 1200 $\mathrm{rpm}$. Cells were subsequently lysed with $4 \mathrm{ml} \mathrm{NP}-40$ ly-

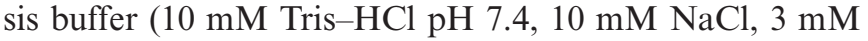
$\mathrm{MgCl}_{2}, 0.5 \% \mathrm{NP}-40$ ) on ice for $5 \mathrm{~min}$ and centrifuged at $1000 \mathrm{rpm}$ for $10 \mathrm{~min}$. Pellets were resuspended in $200 \mu \mathrm{l}$ nuclear freezing buffer (50 mM Tris- $\mathrm{HCl} \mathrm{pH} 8.3,40 \% \mathrm{v} / \mathrm{v}$ glycerol, $5 \mathrm{mM} \mathrm{MgCl}, 0.1 \mathrm{mM}$ EDTA) and incubated with

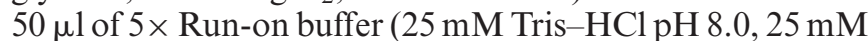
$\mathrm{MgCl}_{2}, 500 \mathrm{mM} \mathrm{KCl}, 1.25 \mathrm{mM}$ ATP, $1.25 \mathrm{mM}$ GTP, 1.25 $\mathrm{mM} \mathrm{CTP}$ ) and $1.25 \mathrm{mM}$ Biotin-labeled UTP (AM8452, Invitrogen) for $40 \mathrm{~min}$ at $37^{\circ} \mathrm{C}$ with $300 \mathrm{rpm}$ shaking. Total RNA was extracted by using RNeasy Kit (74004, Qiagen) according to the manufactory's protocol. Freshly transcribed RNAs with Biotin-labeled UTP were isolated from total RNA by using Dynabeads ${ }^{T M}$ MyOne ${ }^{T M}$ Streptavidin C1 (65001, Invitrogen) according to the manufactory's protocol. In short, $15 \mu l$ beads per reaction were washed with Solution A (DEPC-treated 0.1 M NaOH, DEPC-treated 0.05 $\mathrm{M} \mathrm{NaCl})$, subsequently with Solution $\mathrm{B}(0.1 \mathrm{M} \mathrm{NaCl})$ and finally with Binding and Washing Buffer $(10 \mathrm{mM}$ Tris- $\mathrm{HCl}$ pH 7.5, 1 mM EDTA, 2M NaCl, 1:50 R Nasin ${ }^{\circledR}$ (N2511, Promega)). Prepared Dyna beads were incubated with total RNA for 10 min at RT, washed twice with Binding and Washing Buffer. Isolated RNA was directly reversed transcribed with Moloney murine leukemia virus Reverse Transcriptase (M170B, Promega) followed up with qPCR analysis. Primers used for Nuclear Run-on Assay are listed in Supplementary Table S2.

\section{Western blot analysis}

Cells were grown on $15 \mathrm{~cm}$ culture dishes until $80 \%$ cell density, harvest and lysed with $100 \mu 1$ lysis buffer $(10 \%$ glycine, $1 \%$ Triton X 100, $137 \mathrm{mM} \mathrm{NaCl}, 20 \mathrm{mM}$ Tris $\mathrm{pH} 8,2 \mathrm{mM}$ EDTA pH 8.1). 100 - $300 \mu \mathrm{g}$ protein was loaded on $10-12 \%$ SDS-PAGE and transferred at $4{ }^{\circ} \mathrm{C}$ overnight to a nitrocellulose blotting membrane (A29434119, GE Healthcare) in transfer buffer $(25 \mathrm{mM}$ Tris $\mathrm{pH} 8,192 \mathrm{mM}$ glycine, $5 \%$ methanol). Membranes were blocked at RT for $1 \mathrm{~h}$ with $5 \%$ milk powder and $0.1 \%$ Tween 20 (diluted in PBS), washed in PBS, incubated with primary antibodies at $4{ }^{\circ} \mathrm{C}$ overnight, washed with PBS and incubated with secondary antibodies at RT for $1 \mathrm{~h}$. Membranes were developed using Fusion Fx 7 (Vilber). Images were processed and quantified by using ImageJ. Antibodies used for western blot analysis are listed in Supplementary Table S1.

\section{Northern Blot analysis}

Five microgram total RNA were denaturated at $65^{\circ} \mathrm{C}$ for 15 min in RNA loading dye (50\% formamide, $7.5 \%$ formaldehyde, $1 \times$ MOPS, $0.5 \%$ ethidium bromide) and immediately placed on ice for $5 \mathrm{~min}$. Samples were separated on a $0.9 \%$ agarose gel (diluted in $1 \times$ MOPS) with $80 \mathrm{~V}$ for $2.5-3 \mathrm{~h}$. The gel was soaked in $20 \times \mathrm{SSC}(3 \mathrm{M} \mathrm{NaCl}, 0.3$ $\mathrm{M} \mathrm{Na}$ citrate, adjust to $\mathrm{pH} 7$ ) and RNAs were transferred to Amersham Hybond membrane (RPN303S, GE Healthcare) soaked in $2 \times$ SSC. Membrane was pre-hybridized for $2 \mathrm{~h}$ at $60^{\circ} \mathrm{C}$ with pre-hybridization buffer $(50 \%$ formamide, $0.1 \%$ SDS, $8 \times$ Denhards solution, $5 x$ SSC buffer, $50 \mathrm{mM}$ $\mathrm{NaP}$ buffer, $0.5 \mathrm{mg} / \mathrm{ml}$ t-RNA). Probes were synthesized by $\mathrm{T} 4$ polynucleotide kinase using radioactive $\left[{ }^{32} \mathrm{P}\right]$ y ATP. Membranes were hybridized with radioactive ${ }^{32} \mathrm{P}$-labeled oligonucleotides using pre-hybridization buffer at $60^{\circ} \mathrm{C}$ for $1 \mathrm{~h}$ and subsequently at $37^{\circ} \mathrm{C}$ overnight. Finally, membranes were exposed to X-ray film and quantified with ImageJ after Wang and Pestov (24). For rRNA processing pathway 
analysis we used probes binding to the region ITS1 $\left(5^{\prime} \mathrm{GG}\right.$ GCCTCGCCCTCCGGGCTCCGTTAATGATC $3^{\prime}$ ) and ITS2 on the rDNA (5' CTGCGAGGGAACCCCCAGCC GCGCA 3').

\section{Ribosome preparation}

Ribosome preparation was performed after Penzo et al. (25). $80 \%$ confluent cells were washed, harvest and lysed with cell lysis buffer $(10 \mathrm{mM}$ Tris- $\mathrm{HCl} \mathrm{pH} 7.5,10 \mathrm{mM}$ $\mathrm{NaCl}, 3 \mathrm{mM} \mathrm{MgCl}, 0.5 \%$ Nonidet P40) on ice for $10 \mathrm{~min}$. Samples were centrifuged for $12 \mathrm{~min}$ at $16900 \times \mathrm{g}$ and lysates were incubated with protein synthesis master mix (150 mM HEPES-KOH pH 7.5, $400 \mathrm{mM} \mathrm{KCl,} 250 \mu \mathrm{M} \mathrm{L}-$ amino acid mixture, $1.25 \mathrm{mM}$ GTP, $10 \mathrm{mM}$ ATP, $25 \mathrm{mM}$ creatine phosphate, $2 \mathrm{mM}$ spermidine, $2.5 \mathrm{mM}$ DTT, $5 \mathrm{mM}$ magnesium acetate, $0.9 \mathrm{mg} / \mathrm{ml}$ creatine kinase) for $10 \mathrm{~min}$ at $37^{\circ} \mathrm{C}$. Subsequently, samples were transferred to a sucrose gradient, consisting of a bottom sucrose layer $(30 \mathrm{mM}$ HEPES-KOH pH 7.5, $70 \mathrm{mM} \mathrm{KCl,} 2 \mathrm{mM}$ magnesium acetate, $1 \mathrm{mM}$ DTT, $1 \mathrm{M}$ sucrose) and a high-salt-top layer (30 $\mathrm{mM}$ HEPES KOH $\mathrm{pH} 7.5,0.5 \mathrm{M} \mathrm{KCl}, 2 \mathrm{mM}$ magnesium acetate, $1 \mathrm{mM}$ DTT, $0.7 \mathrm{M}$ sucrose). After ultracentrifugation (Optima ${ }^{\text {TM }}$ MAX-XP Ultracentrifuge, Beckman Coulter) for $15 \mathrm{~h}$ at $4^{\circ} \mathrm{C}$ with $110000 \times \mathrm{g}$, pelleted ribosomes were resuspended in ribosome solution $(10 \mathrm{mM}$ Tris- $\mathrm{HCl}$ $\mathrm{pH}$ 7.5, 2mM magnesium acetate, $100 \mathrm{mM}$ ammonium acetate).

\section{Ribosome stability assay using BisANS}

Five microgram isolated ribosomes were treated with $2 \mathrm{M}$ urea for $2 \mathrm{~h}$. Conformational changes of proteins were detected by the probe BisANS (4,4'-dianilino-1,1'-binaphthyl$5,5^{\prime}$-disulfonic acid, dipotassium salt). BisANS is nonfluorescent in water and only becomes appreciably fluorescent when bound to the hydrophobic site of proteins. Hence, BisANS is a sensitive indicator of protein unfolding. Fluorescent was detected by a plate reader Varioskan ${ }^{\mathrm{TM}}$ LUX (Thermofisher Scientific) using excitation $375 \mathrm{~nm} / \mathrm{emission}$ $500 \mathrm{~nm}$.

\section{Mass spectrometry analysis}

Mass spectrometry analysis of isolated ribosomes from NP-TTD cell line TTD218UT and reconstituted cell line 218UT TFIIE $\beta$ were performed by the Bavarian Center for Biomolecular Mass Spectrometry, Technical University Munich (Germany). Label-free quantification of mass spectrometry data was analyzed using Excel and the program software R Studio.

\section{Fluorescence in situ hybridization}

Fluorescence in situ hybridization was performed after (26). In short, cells were seeded on polylysine covered slides and let grow until $80 \%$ cell density. After fixation with 4\% paraformaldehyde $\left(4^{\circ} \mathrm{C}\right)$ for $12 \mathrm{~min}$ at RT, cells were washed twice with PBS and sequentially permeabilized with $0.3 \%$ Triton X-100/PBS for $10 \mathrm{~min}$ at RT. Cells were washed twice with washing buffer ( $2 \times \mathrm{SSC}, 10 \%$ formamide) and hybridization was performed in hybridization buffer $(10 \%$ formamide, $2 \times$ SSC, $0.5 \mu \mathrm{g} / \mu 1 \mathrm{tRNA}, 10 \%$ dextran sulfate, $50 \mu \mathrm{g} / \mathrm{ml} \mathrm{BSA}, 10 \mathrm{mM}$ ribonucleoside vanadyl complexes, $0.5 \mu \mathrm{g} / \mu \mathrm{l}$ probe) for $3 \mathrm{~h}$ at $37^{\circ} \mathrm{C}$. After washing cells twice with washing buffer and once with PBS, cells were incubated in DAPI solution $(0.1 \mu \mathrm{g} / \mathrm{ml})$ for $5 \mathrm{~min}$ at RT. Finally, cells were washed twice in PBS and mounted. Images were taken with a Compact Fluorescence Microscope (BZ-X800E, Keyence). The CTCF (corrected total cell fluorescence) in the nucleolus (ITS1 probe) or the nucleus (U2) were analyzed in at least 100 cells per cell line by using ImageJ and experiments were performed at least twice per cell line. For Fluorescence in situ hybridization we used probes binding to ITS1 (CCT*CGCCCTCCGGGC T*CCGTTAATGAT*C) and U2 (A*AACTGATAAGAA CAGATACT*ACACTTGATCTTAGCCAAA*A). * represents the nucleotide conjugated to Cy 3 in ITS1 probe or $\mathrm{Cy} 5$ in $\mathrm{U} 2$ probe.

\section{Polysomal profiling}

$5 \times 107$ cells were treated with $100 \mu \mathrm{g} / \mathrm{ml}$ Cycloheximide (C7698-1G, Sigma) for $30 \mathrm{~min}$ at $37^{\circ} \mathrm{C}$. Cells were collected by scraping to $50 \mathrm{ml}$ falcon tubes and centrifuging for $5 \mathrm{~min}$ $1200 \mathrm{rpm}$. Pelleted cells were mechanically disrupted with a Dounce homogenizer in 1.5 × Dignam A (incl. 1:1000 DTT, 1:50 cOmplete proteinase inhibitor cocktail mix (Roche), $100 \mu \mathrm{g} / \mathrm{ml}$ Cycloheximide). Samples were rested on ice for $1 \mathrm{~min}$ and subsequently centrifuge for $10 \mathrm{~min}$ at $1000 \times \mathrm{g}$ at $4^{\circ} \mathrm{C}$. The supernatant was collected and centrifuged twice for $5 \mathrm{~min}$ at $12000 \times \mathrm{g}$ at $4^{\circ} \mathrm{C}$. The new supernatant was considered as the cytoextract and $500 \mu \mathrm{g}$ cytoextract was loaded on a $10-50 \%$ sucrose gradient. After ultracentrifugation (OptimaTM MAX-XP Ultracentrifuge, Beckman Coulter) for $3 \mathrm{~h}$ at $4{ }^{\circ} \mathrm{C}$ with $100000 \times \mathrm{g}$, the gradient was analyzed at $\mathrm{OD}_{260 \mathrm{~nm}}$. The linear sucrose gradient as well as the measurements at $\mathrm{OD}_{260 \mathrm{~nm}}$ were obtained by Piston Gradient Fractionator $^{\mathrm{TM}}$ (BioComp).

\section{Luciferase-based translation fidelity assay with plasmid transfection}

The translation fidelity assay via plasmid transfection includes the control reporter luciferase Renilla and experimental reporters Firefly (PC, MUT). Renilla and Firefly were expressed on separate plasmids (kindly provided by Vera Gorbunova). Cells were cultured in $10 \mathrm{~cm}$ culture dishes until $80 \%$ cell density. $15 \times 10^{4}$ cells were harvest and co-transfected with $0.1 \mu \mathrm{g}$ control plasmid Renilla and $5 \mu \mathrm{g}$ reporter plasmid Firefly (Neg or Mut) via electroporation using Neon ${ }^{T M}$ Transfection System (MPK1096, Invitrogen) with following parameters: $1100 \mathrm{~V}, 20 \mathrm{~ms}$ and $2 \times$ pulses. Subsequently, cells were seeded in $5 \times 10^{4}$ cells/well in white 96-well plates and were grown $24 \mathrm{~h}$. Luciferase activities were detected by using Dual-Glo ${ }^{\circledR}$ Luciferase Assay System (E2920, Promega) according to the manufactory's protocol.

\section{Luciferase-based translation fidelity assay with mRNA trans- fection}

The translation fidelity assay via mRNA transfection includes the control reporter luciferase Renilla and experimental reporters Firefly (PC or MUT). Renilla and Firefly 
were expressed on one plasmid (kindly provided by Markus Schosserer). Plasmids were transcribed to mRNAs by using Ampli Cap-Max T7 High Yield Message Marker Kit (C-ACM04037, CellScript) according to the manufactory's protocol. $10^{5}$ cells/well in $100 \mu \mathrm{l}$ culture medium were seeded in white 96-well plate and were grown overnight. 500ng mRNA/well in $50 \mu$ l OptiMEM (31985070, Gibco) and $1 \mu \mathrm{l} /$ well of Lipofectamine ${ }^{\circledR}$ MessengerMAX mRNA Transfection Reagent (LMRNA003, Invitrogen) in $50 \mu \mathrm{l}$ OptiMEM were incubated for 10 min at RT. mRNA dilution and Lipofectamine dilution were mixed and incubated for further $15 \mathrm{~min}$ at RT. After removing the old media from cells, $100 \mu \mathrm{l}$ of mRNA-Lipofectamine-OptiMEM mixture were transferred to each well and cells were grown for $24 \mathrm{~h}$. Luciferase activities were detected by using Dual-Glo ${ }^{\circledR}$ Luciferase Assay System (E2920, Promega) according to the manufactory's protocol.

\section{Protein synthesis analysis}

Protein synthesis was detected by using Protein Synthesis Assay Kit (601100, CaymanChemical) according to the manufactory's protocol. Briefly, $2.5 \times 10^{4}$ cells $/ \mathrm{ml}$ were grown in white 96-well plate overnight, incubated with OPP (O-Propargyl-puromycin) working solution for $1 \mathrm{~h}$, fixed, and stained with 5 FAM-Azide solution for $30 \mathrm{~min}$. OPP binds to newly synthesized polypeptides and 5 FAM-azide is fluorescent upon binding to OPP. Fluorescence was detected by using a plate reader Varioskan ${ }^{\top \mathrm{TM}}$ LUX (Thermofisher Scientific) using excitation $485 \mathrm{~nm} /$ emission 535 $\mathrm{nm}$.

\section{${ }^{35}$ S Methionine labeling}

Protein translation was analyzed by using metabolic labeling of cells with ${ }^{35} \mathrm{~S}$ methionine. Therefore, $5 \times 10^{4}$ cells per reaction were harvest in $1.5 \mathrm{ml}$ reaction tube by centrifuging for $5 \mathrm{~min}$ at $3000 \mathrm{rpm}$, and incubated at $37^{\circ} \mathrm{C}$ for $30 \mathrm{~min}$ in $100 \mu \mathrm{l}$ methionine-free DMEM (21013-024, Gibco) supplemented with $10 \%$ FBS and 1\% penicillin-streptomycin. Subsequently, $10 \mu \mathrm{l}$ culture medium with $1 \%{ }^{35}$ S-labeled methionine was added to cells and cells were incubated for further $1 \mathrm{~h}$. After centrifuging cells for $5 \mathrm{~min}$ at $3000 \mathrm{rpm}$, cell pellet was resuspended in $100 \mu 1 \mathrm{mg} / \mathrm{ml} \mathrm{BSA}$ and each reaction was vortex for $3 \mathrm{~s} .1 \mathrm{ml}$ of cold $10 \%$ TCA was added, vortexed for $3 \mathrm{~s}$ and reactions were incubated on ice for $1 \mathrm{~h}$. Reaction was transferred onto glass fiber prefilters (Merck, APFC02500) and washed with cold 10\% TCA and subsequently with cold $70 \%$ ethanol. Glass fiber prefilters were air dried for $5 \mathrm{~min}$ and the amount of ${ }^{35} \mathrm{~S}$-labeled methionine was analyzed with $5 \mathrm{ml}$ liquid scintillation cocktail Ultima Gold ${ }^{\mathrm{TM}}$ (6013329, PerkinElmer) by Liquid Scintillation Analyzer Tri-Carb 4910 TR (PerkinElmer).

\section{S Proteasome activity analysis}

20S Proteasome activity was determined by using $20 \mathrm{~S}$ Proteasome Assay Kit (10008041, CaymanChemical) according to the manufactory's protocol. In short, $5 \times 10^{5}$ cells/well in $100 \mu \mathrm{l}$ culture medium were seeded in white 96-well plate, lysed, and incubated with a 20 S specific substrate solution for $1 \mathrm{~h}$. The $20 \mathrm{~S}$ specific substrate is fluorescent upon cleavage and fluorescence was detected by using a plate reader Varioskan ${ }^{\mathrm{TM}}$ LUX (Thermofisher Scientific) using excitation $360 \mathrm{~nm} /$ emission $480 \mathrm{~nm}$.

\section{Heat sensitivity analysis}

Heat sensitivity analysis was adapted from Treaster and colleagues (27). Cells were grown on $15 \mathrm{~cm}$ culture dished to $80 \%$ cell density. $4 \times 10^{6}$ cells were harvest and its PCV (packed cell volume) was estimated. Cells were dissolved in $1.5 \times$ PCV of Dignam A buffer $(10 \mathrm{mM} \mathrm{KCl}, 10 \mathrm{mM}$ Tris $\mathrm{pH} 7.9,1.5 \mathrm{mM} \mathrm{MgCl}_{2}, 1: 50 \mathrm{cOmplete}$ proteinase inhibitor mix) for $15 \mathrm{~min}$ on ice. Cells were lysed by passing cells 50 times through a $23 \mathrm{G}$ syringe. Cytoplasmic extract was separated from nuclei and cell debris by centrifugation for $5 \mathrm{~min}$ at $4000 \mathrm{rpm}$ at $4{ }^{\circ} \mathrm{C}$ and subsequently by ultracentrifuge for 1 $\mathrm{h}$ with $100000 \times \mathrm{g}$ at $4^{\circ} \mathrm{C}$. $150 \mu \mathrm{g}$ of protein lysate was heattreated at $99^{\circ} \mathrm{C}$ for $15 \mathrm{~min}$ and subsequently centrifuged for 5 min with $14000 \mathrm{rpm}$ at $4^{\circ} \mathrm{C}$. The pellet was resuspended in $10 \mu 14 \mathrm{M}$ urea and the protein concentration of both pellet and supernatant was determined by using the method of Bradford (5000006, Bio-Rad). Finally, the percentage of pelleted protein in relation to total protein was calculated.

\section{Growth kinetic}

$2 \times 10^{5}$ cells were seeded per well in a 6 -well culture plate. For each time point 3 , wells were detached using $1 \mathrm{x}$ trypsin and manually counted using a hemocytometer (Neubauer chamber, $0.100 \mathrm{~mm}$ depth, $0.0025 \mathrm{~mm}^{2}$ area). Cells were counted every $48 \mathrm{~h}$ over a period of 10 days.

\section{Statistical analysis}

All plots were created by using GraphPad Prism version 7.0.3, Excel Microsoft Office Professional Plus 2013 or R version 3.4.4. Differences between means \pm standard deviation (SD) of at least three independent experiments were assessed with ONE Way ANOVA when comparing samples, and with two-way ANOVA followed by Sidak post-hoc analysis, when comparing samples in groups, unless differently described. ns $P>0.05$, * $P \leq 0.05$, ** $P \leq 0.01$, *** $P \leq 0.001$, **** $P \leq 0.0001$.

\section{RESULTS}

TFIIE is enriched in transcriptionally active nucleoli and binds to ribosomal DNA

TFIIE mutations cause TTD, a disease mainly provoked by mutations in the multifunctional TFIIH complex. As the TFIIH complex plays an essential role in RNA polymerase I transcription (10), we have addressed the question if TFIIE is also involved in ribosomal biogenesis. RNA polymerase I transcription takes place in the nucleolus, the densest cellular organelle. To investigate if TFIIE localizes to the nucleolus, co-localization studies employing confocal microscopy with nucleolar proteins were performed and further refined by super resolution STED microscopy (Figure 1A). We observed a distinct enrichment of TFIIE $\beta$ in the nucleoli and 

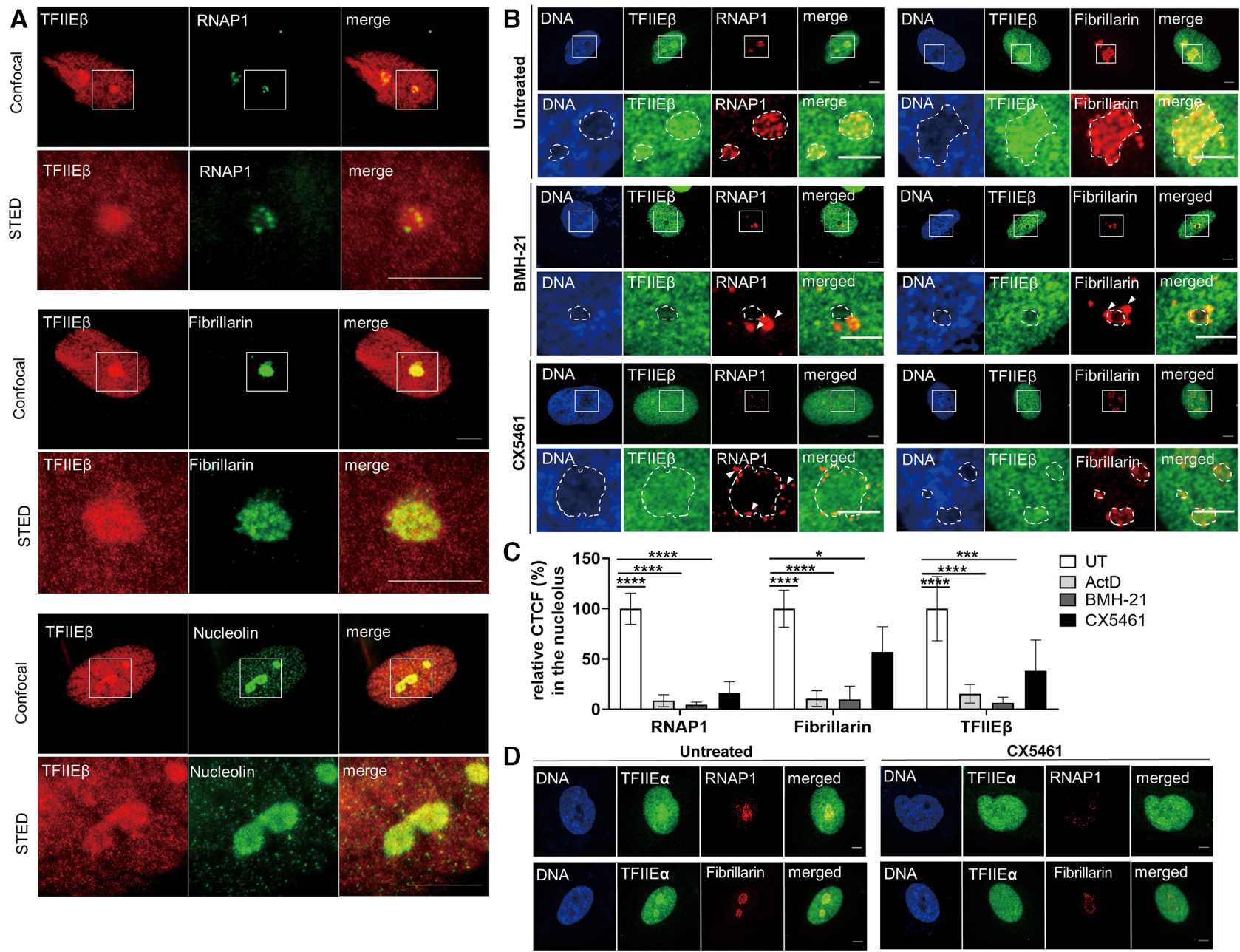

Figure 1. Both TFIIE subunits localize to the nucleolus. (A) Super resolution STED microscopy images showing co-localization of TFIIE $\beta$ with nucleolus markers RNA polymerase I, Fibrillarin and Nucleolin. Scale bar $5 \mu \mathrm{m}$. More STED images of TFIIH (as a positive control), TFIIF and TFIIE $\beta$ after specific inhibition of RNA polymerase I transcription by BMH-21 are given in the Supplement S1A-B. Analysis of STED images are given in the Supplement S2A-C. (B) Confocal immunofluorescence microscopy $(100 \times)$ of WT cells indicates co-localization of TFIIE $\beta$ with RNAP1 and Fibrillarin. Inhibition of RNA polymerase I transcription in WT cells by $1 \mu \mathrm{M}$ BMH-21 or $1 \mu \mathrm{M}$ CX5461 result in a re-distribution of both TFIIE from the nucleolar enrichment and an organization of RNA polymerase I to nucleolar caps (arrows). Scale bar $5 \mu \mathrm{m}$. More images of TFIIEß localization after Actinomycin D treatment are given in the Supplement S1C. (C) Quantification of CTCF (corrected total cell fluorescence) of IF performed in (B) indicating reduced TFIIE $\beta$ staining in the nucleolus after inhibition of RNA polymerase I transcription by Actinomycin D (ActD), BMH-21 or CX5461. (D) Confocal immunofluorescence microscopy (100X) of WT cells untreated and treated with CX5461 indicating co-localization of TFIIE $\alpha$ with RNA polymerase I and Fibrillarin. Inhibition of RNA polymerase I transcription results in a non-significant re-distribution of TFIIE $\alpha$ from the nucleolar enrichment. Scale bar $5 \mu \mathrm{m}$. Quantification of co-localization studies of TFIIE $\alpha$ upon treatment with CX5461 are given in the Supplement S2D. Data are represented as mean \pm SD of at least three independent experiments. Measures were performed in at least 50 cells. ${ }^{*} P \leq 0.05,{ }^{* * *} P \leq 0.001, * * * * P \leq 0.0001$.

a close co-localization with RNA polymerase I, Fibrillarin and Nucleolin. Remarkably, this enrichment is lost when RNA polymerase I transcription is blocked by the specific inhibitors BMH 21, CX5461 and Actinomycin D leading to a re-organization of RNA polymerase I in nucleolar caps (Figure 1B-C, Supplementary Supplement S1B, C, Supplement S2A, C) The large subunit of TFIIE, TFIIE $\alpha$ showed a comparable distribution when co-stained with RNA polymerase I (Figure 1D, Supplement S2D left panel). This data indicates that both subunits of TFIIE are enriched in the nucleoli. TFIIH, known to be involved in RNA polymerase I transcription, can also be traced in the nucleolus (Supplement S1A, SupplementS2B left panel). Interestingly, TFIIF, a general transcription factor of RNA polymerase II and one interaction partner of TFIIE, is not enriched in the nucleolus (Supplement S1A, SupplementS2B right panel), indicating an RNA polymerase II- independent localization of TFIIE in the nucleolus. As the TFIIE complex binds to the core promoter DNA of RNA polymerase II genes $(14,22)$ we further explored a potential binding of TFIIE to the ribosomal DNA using ChIP experiments. In fact, binding of TFIIE to the rDNA at the end of the coding region is distinctly traceable, while TFIIE did not bind to the promoter of the rDNA. A specific binding of both subunits of TFIIE to the rDNA is clearly detectable by semiquantitative and quantitative PCR (Figures 2A, left side, Figure 2B, Supplement S3A). These findings are supported by further experiments depicted in Figure 2A, right pan- 

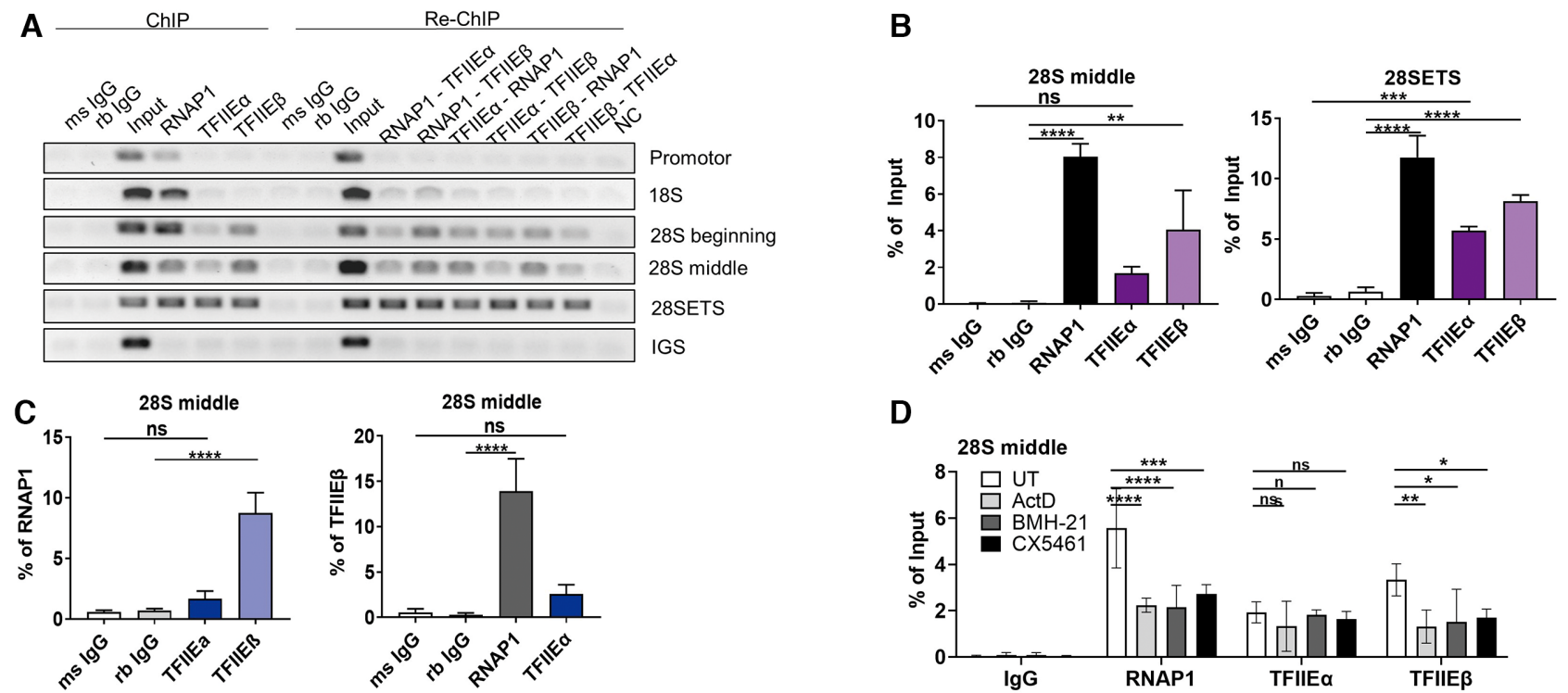

D
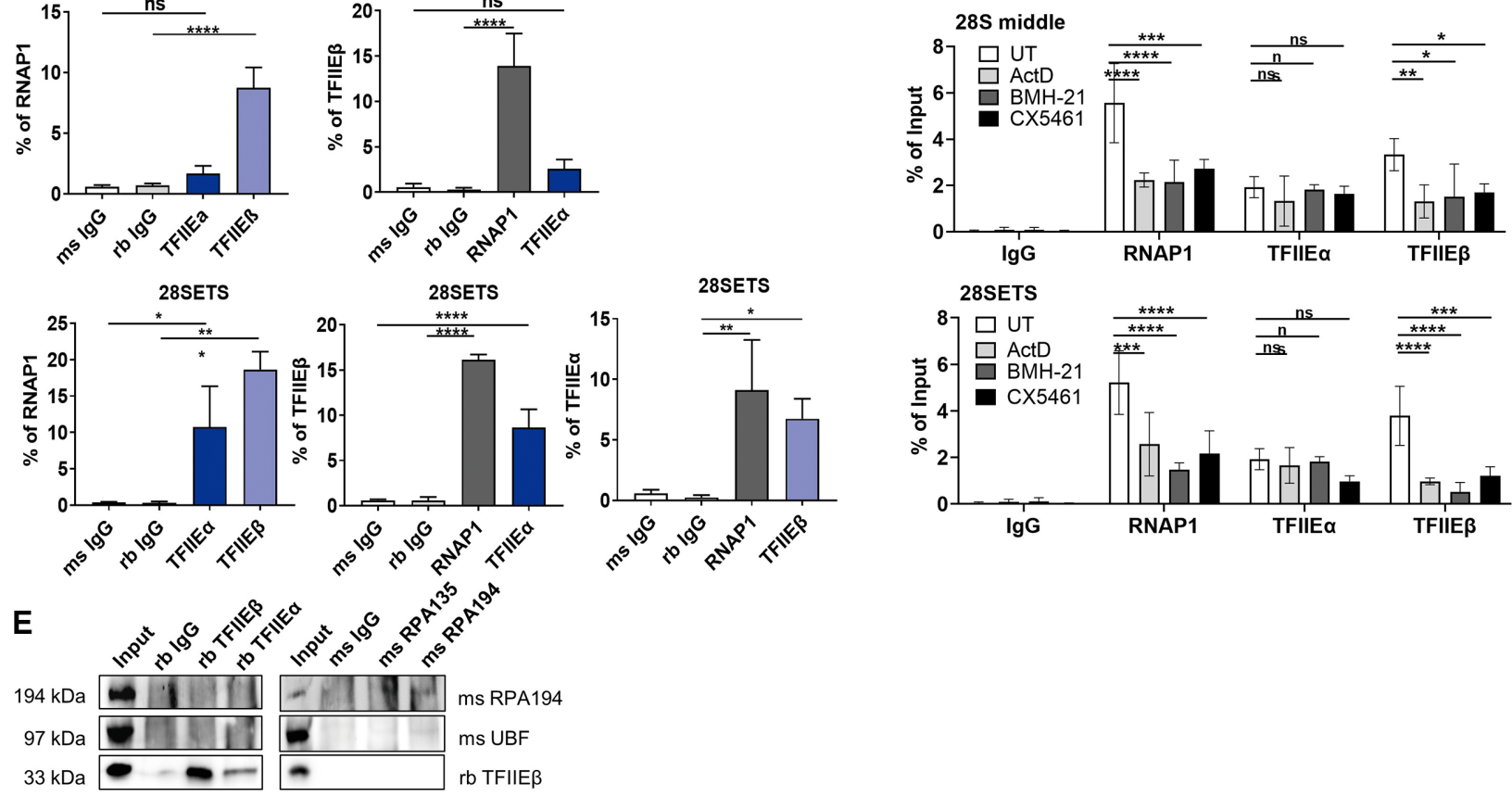

Figure 2. TFIIE associate to active rDNA genes. (A) Semi-quantitative PCR analysis of ChIP and sequential ChIP (Re-ChIP) of TFIIE subunits and RNA polymerase I shows no binding of TFIIE $\beta$ to the beginning and middle of the rDNA (Promotor, 18S), but to the 28S rDNA coding region (28S beginning - 28SETS). Re-ChIP semi-quantitative analysis shows binding of TFIIE to the same rDNA molecules as RNAP1. Semi-quantitative PCR analysis of the ribosomal intergenic spacer (IGS) region serves as a negative control. (B) Quantitative qPCR analysis of ChIP performed in (A) shows significant binding of TFIIE $\beta$ to the whole $28 \mathrm{~S}$ rDNA coding region, while TFIIE $\alpha$ only associates to the end of the $28 \mathrm{~S}$ rDNA coding region (28SETS). More quantitative qPCR analysis of ChIP at other regions of the rDNA are given in the Supplement S3A. Semi-quantitative and quantitative analysis of ChIP of additionally UBF are given in the Supplement S3B-D. (C) Quantitative qPCR analysis of sequential ChIP (Re-ChIP) performed indicates significant binding of TFIIE subunits to the same rDNA molecule as RNA polymerase I. (D) Quantification of ChIP analysis showing reduced TFIIE $\beta$ and RNA polymerase I binding to the $28 \mathrm{~S}$ coding region (28S middle, 28SETS after inhibition of RNA polymerase I transcription by Actinomycin D (ActD), BMH-21 or CX5461. Data are represented as mean $\pm \mathrm{SD}$ of at least three independent experiments. ns $P>0.05, P * P \leq 0.05, * * P \leq 0.01, * * * P \leq 0.001, * * * * P \leq 0.0001$. ms and $\mathrm{rb}$ IgG are mouse and rabbit IgG controls, respectively. (E) Co-Immunoprecipitation of TFIIE subunits (TFIIE $\alpha$, TFIIE $\beta$ ) and RNA polymerase I subunits (RPA194, RPA135) showing direct interaction of TFIIE $\beta$ and TFIIE $\alpha$, RPA194 and RPA135, but no direct interaction between TFIIE subunits with RNA polymerase I subunits.

els and Figure 2C. In fact, using ChIP-re-ChIP experiments we show that both TFIIE subunits were precipitated with RNA polymerase I antibodies and antibodies against the basal RNA polymerase I transcription factor UBF (Supplement S3B-D). These data imply that TFIIE, RNA polymerase I and UBF bind to the same rDNA molecules constituting the transcriptionally active fraction of the rDNA. This rDNA binding is significantly reduced for TFIIE $\beta$ and RNA polymerase I, when treating the cells with Actinomycin D, BMH21 and CX5461 (Figure 2D). However, a direct interaction of TFIIE with RNA polymerase I could not be observed in co-immunoprecipitation assay (Figure 2E, Supplement S3E). Thus, TFIIE localizes to the nucleolus and associates with transcriptional active rDNA molecules providing evidence for a possible role of TFIIE in ribosomal biogenesis.

\section{Mutations in TFIIE $\beta$ affect rDNA transcription and process- ing}

The two fibroblasts cell lines TTD218UT and TTD28N used in this study were isolated from two different TTD patients bearing the same homozygote mutation in D187Y (Supplement S4A, $(13,21)$ ). Both patient cell lines were reconstituted with a wild-type TFIIE $\beta$ fused to GFP: 218 UT TFIIE $\beta$ and $28 \mathrm{~N}$ TFIIE $\beta$. For the following experiments the patient cell lines were compared to a healthy control (WT) and the respective reconstituted cell line. 
As previously described (13), employing western blot analysis we confirmed reduced protein concentration of TFIIE $\beta$ in both TTD cell lines indicating that the mutation affects TFIIE $\beta$ protein stability (Supplement S4C, D). By contrast, protein levels of TFIIH subunits are stable (Supplement S4C, E). As reported, the abundance of TFIIE $\alpha$ protein is diminished although there are no mutations. These findings were confirmed by immunofluorescence staining of both TFIIE subunits in TTD cells compared to reconstituted cell and WT cell lines (Supplement S4B).

To investigate if the reduced TFIIE levels in TTD cells may impact on RNA polymerase I transcription, we examined gene occupancy of the rDNA by RNA polymerase I in more detail. ChIP experiments were used for the analysis of $16 \mathrm{rDNA}$ regions (Figure 3A) by qPCR to map the density of RNA polymerase I on the ribosomal DNA template and to create a binding profile. The binding profile was then compared between wild-type, reconstituted and TFIIE $\beta$ mutated cell lines. As depicted in Figure 3B, the rDNA binding profile of RNA polymerase I is significantly altered in both TTD patient cell lines, with a significant reduction of rDNA binding by RNA polymerase I throughout the entire 28S rDNA. Nuclear Run-on analysis revealed a reduced level of promotor-distal pre-rRNA synthesis. This finding is in line with the reduced gene-occupancy of RNA polymerase I (Supplement S5A). These results imply that the abundance of TFIIE on the rDNA is essential for the proper association with the template and elongation activity of the polymerase.

Since TFIIE $\beta$ mutations in TTD cells reduce the binding of RNA polymerase I to the end of the rDNA, we further assessed $47 \mathrm{~S}$ pre-rRNA levels and mature rRNA abundance by Northern blot analysis. No significant reduction of 47S pre-rRNA was detected (Supplement S5B), however, the amount of mature 18S rRNA was significantly reduced in TTD cells (Figure 3C). The pre-rRNA precursor is cotranscriptionally processed, matured and assembled in preribosomal particles (1). Therefore, and stimulated by previous work (12), we were interested to monitor the processing steps from the pre-rRNA to the mature product by Northern blot analysis. In Figure 3D, the processing steps are schematically depicted and the position of the probes used to perform Northern blots are indicated. This technique allows to visualize and quantitate all processing intermediates within the rRNA maturation pathway. Northern blot analysis and ratio analysis of multiple precursors (RAMP) profile quantification (24) revealed an increased tendency to the accumulation of $21 \mathrm{~S}$ and a significant accumulation of $18 \mathrm{~S}-\mathrm{E}$ processing intermediate in TTD cells as opposed to WT and reconstituted cells (Figure 3E, F, Supplement S6A, B).

Taken together these results show, that mutation in TFIIE $\beta$ weakens the interaction of RNA polymerase I with the template that is followed by the accumulation of processing intermediates.

\section{TFIIE $\beta$ mutation affects ribosomal stability and perfor- mance}

Next, we asked the question if and how disturbed ribosomal biogenesis affects ribosomal composition and the trans- lation process. While mature 18S rRNA is the structural and functional backbone of the small ribosomal subunit $40 \mathrm{~S}$, the 5.8S, 28S rRNA and 5S (a product of RNA polymerase III) are components of the large ribosomal subunit 60S. Since our TTD cells show reduced mature 18S rRNA abundance due to disturbances in rRNA processing, we isolated ribosomes from reconstituted and TTD cells after sucrose gradient centrifugation (25) and performed quantitative analysis of the ribosomal composition by mass spectrometry (Figure 4A, left panel). Although not reaching significance, all detectable ribosomal proteins of the small subunit $40 \mathrm{~S}$ are reduced in TTD ribosomes compared to the reconstituted cell line. This finding is in line with the reduced presence of mature 18S rRNA in TTD cells. To confirm our mass spectrometry data, we picked three ribosomal proteins of the big and small ribosomal subunit and analyzed their protein level in whole-cell lysate and in purified ribosomes. We were able to visualize a relative underrepresentation of proteins of the small ribosomal subunit in isolated ribosomes (Figure 4A right panel, Supplement S6C-E).

Final maturation of the 18S rRNA by cleavage of the 18SE occurs in the cytoplasm after RPS15-mediated export of the pre-40S particle from the nucleoplasm (26). As RPS15 was found to be underrepresented in isolated TTD ribosomes, we asked the question if the export of pre-40S particles might be disturbed. Fluorescence-in-situ hybridization (FISH) was used to visualize the $18 \mathrm{~S}-\mathrm{E}$ in control and affected cells. As depicted in Figure 4B there is nucleoplasmic ITS1 staining in TTD cells traceable, that indicates, in conjunction with the reduced RPS15 content, a maturation defect of the $40 \mathrm{~S}$ ribosomal subunit. To investigate if this maturation defect is mirrored in the distribution of cytoplasmic ribosomal subunits, polysomal profiling was performed. This method allows a 'snapshot' of ribosomal composition and subunit abundance and revealed that TFIIE $\beta$ mutation reduces the cytoplasmic content of the 40S ribosomal subunit as shown in Figure 4C.

Sucrose gradient centrifugation was employed to isolate ribosomes to assess the unfolding stability of ribosomal proteins. The purified ribosomes were incubated with the chaotropic reagent urea and the subsequently exposed hydrophobic residues of unfolded ribosomal proteins were quantified by the fluorophore BisANS. The stability of proteins against unfolding by urea is a hallmark of long-lived species (27-28) and is considered as an indicator for translational accuracy (29). After urea challenge, ribosomal preparations of both TTD cell lines depict increased amounts of unfolded ribosomal proteins (Figure 4D) indicating a qualitative disturbance of the corresponding ribosomes. These results indicate that the amount of misfolded proteins in ribosomal preparations of TFIIE $\beta$ mutant cells is higher than in reconstituted and control cells.

\section{TFIIE $\beta$ mutation results in a disturbed translational fidelity,} protein homeostasis and cell growth

To further unravel the functional base of the elevated load of misfolded proteins in ribosomal proteins, we assessed the error rate of the translation process itself. For this purpose, a luciferase-based translation fidelity assay was used. This assay includes a control reporter Renilla and a Firefly re- 
A

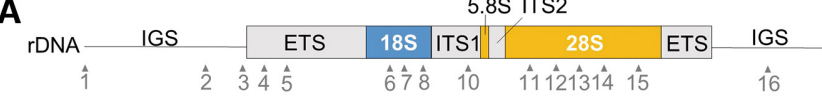

B
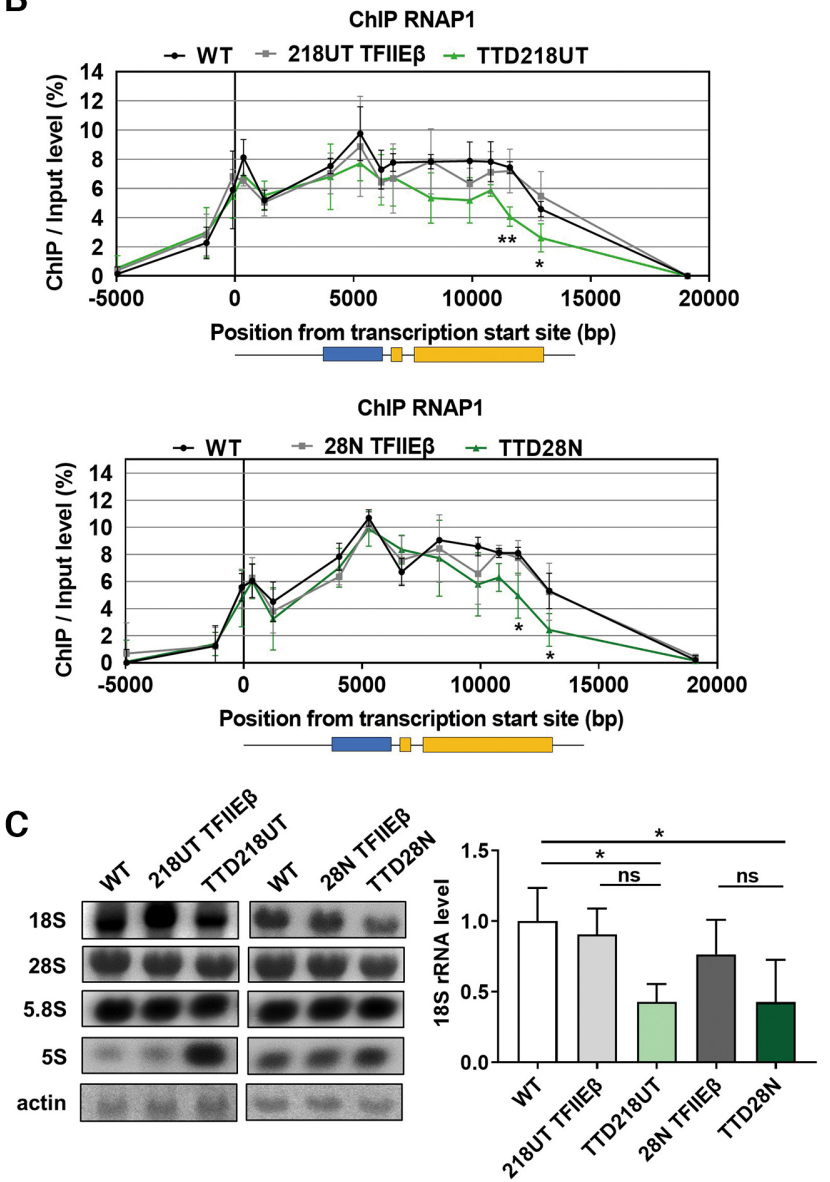

D
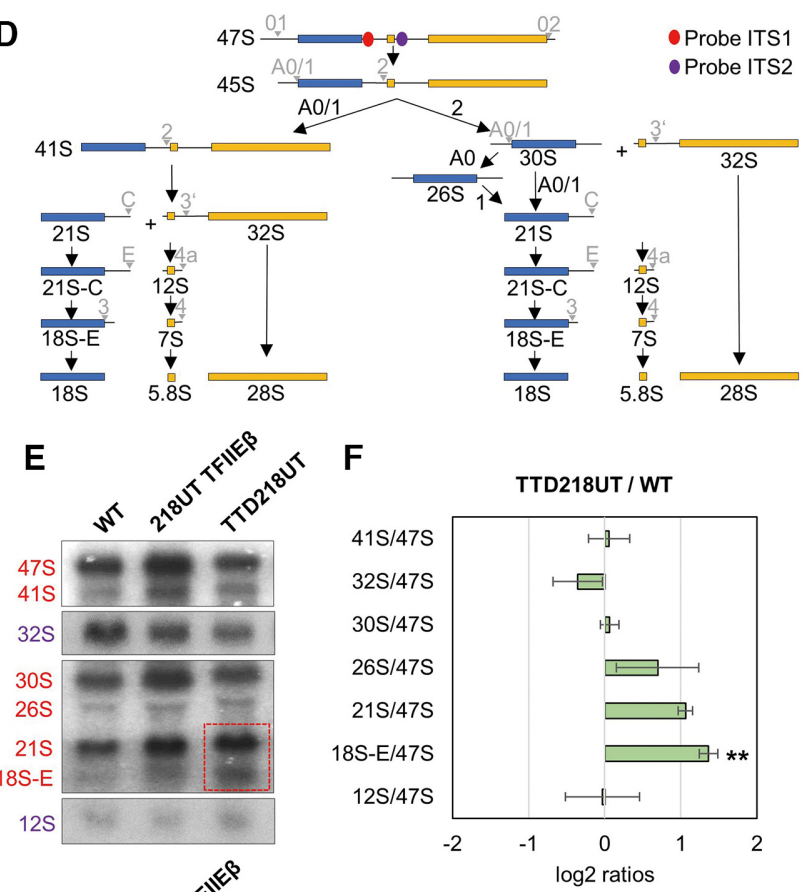

TTD28N / WT
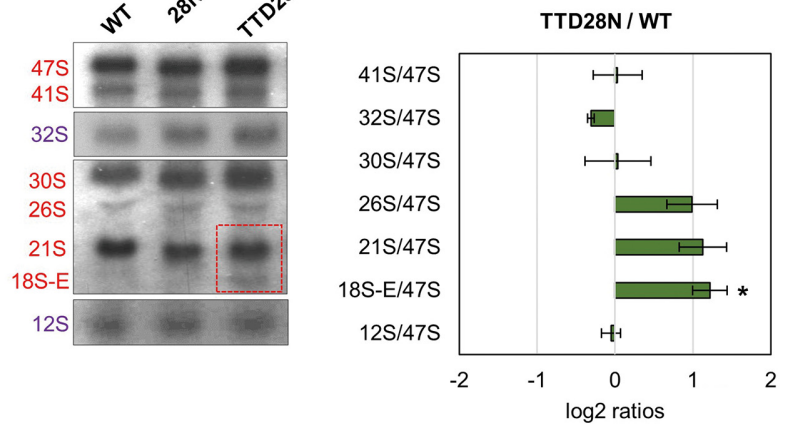

Figure 3. TFIIE influences RNA polymerase I gene occupancy and rRNA processing. (A) Schema of the human rDNA unit. The non-coding region ETS, ITS1 and ITS2 (gray) and coding regions 18S (blue), 5.8S and 28S (both in orange) are illustrated. Primers used for ChIP analysis are indicated by arrowheads and numbers. Exact primer sequences are given in Table S2. (B) Quantitative qPCR ChIP analysis of RNAP1 in WT, reconstituted and TTD cells indicates reduced binding of RNAP1 to the end of the 28S rRNA coding rDNA (region 14 and 15) in TTD cells. (C) Left: Northern Blot analysis of mature 18S, 28S, 5.8S and 5S in WT, reconstituted and TTD cells. Right: Quantification of mature rRNA relative to actin shows decreased mature 18S level in TTD cells compared to WT cells. Quantification of 47S pre-rRNA, 28S, 5.8S and 5S mature rRNA are given in the Supplement S5B. (D) Schema of the rRNA processing pathway in human cells; adapted from (45). ITS1 and ITS2 probes positions are marked in red and purple, respectively. (E) Northern Blot of WT, reconstituted and TTD cells show accumulation of $21 \mathrm{~S}$ and 18S-E levels in TTD cells. Red and purple color code indicates rRNA species detected by ITS1 and ITS2 probe, respectively. Full images of the probed membrane are given in the Supplement S5B. (F) Analysis of the northern blots in (E) are displayed as Ratio Analysis of Multiple Precursors (RAMP) profiles;(24). Data are represented as mean \pm SD of at least three independent experiments. ns $P>0.05, P * P \leq 0.05, * * P \leq 0.01$.

porter containing a point mutation $\mathrm{K} 529 \mathrm{~N}$, which inactivates the Firefly luciferase (Figure 5A). The luciferase Firefly MUT stays inactive with correct translation of the point mutation, whereas luminescence of the Firefly MUT is detectable only in the case that erroneous translation occurs. Plasmids expressing these constructs were co-transfected in WT, reconstituted and TTD cells. Strikingly, both TTD cell lines show an increased luminescence indicative of a higher error rate when compared to the WT and reconstituted cells (Figure 5B left panels).To exclude that the re-activation of luciferase is due to errors in RNA polymerase II transcription, we transfected mRNA into cells. To further guarantee that Renilla: Firefly luciferase is transfected in a ratio of 1:1, plasmids expressing a fusion-protein of Renilla and Firefly were transcribed by means of a T7 kit and transfected to WT, reconstituted and TTD cells (Figure 5B right panels). As observed in the translational fidelity assay with plasmid transfection, TTD cells depict similar high luciferase activity of Firefly MUT after mRNA transfection. We therefore conclude, that the TFIIE $\beta$ mutation in TTD cells fundamentally affects the accuracy of protein synthesis at the ribosome leading to the enrichment of misfolded proteins in the ribosome itself.

Protein homeostasis is sustained by the balance of protein synthesis, maintenance and degradation. As our results unraveled a disturbance in ribosomal accuracy, we investigated the impact of translation on protein homeostasis in TTD cells. First, we detected the rate of translational initiation 

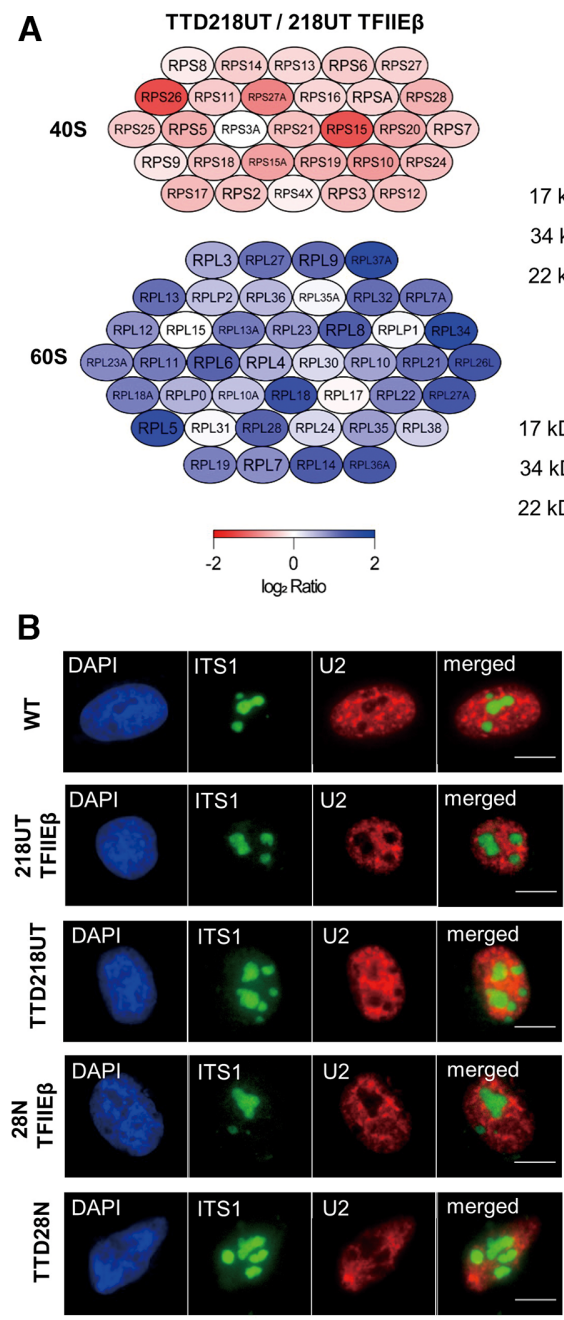
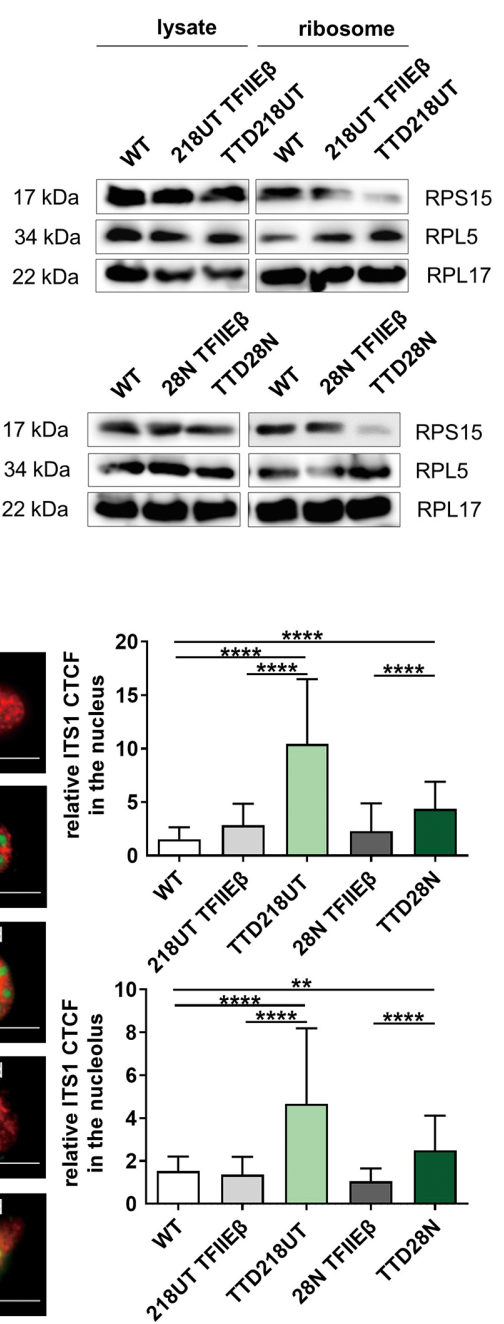
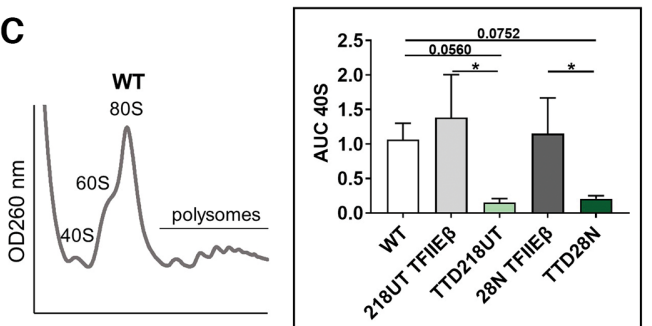

218UT TFIIE $\beta$
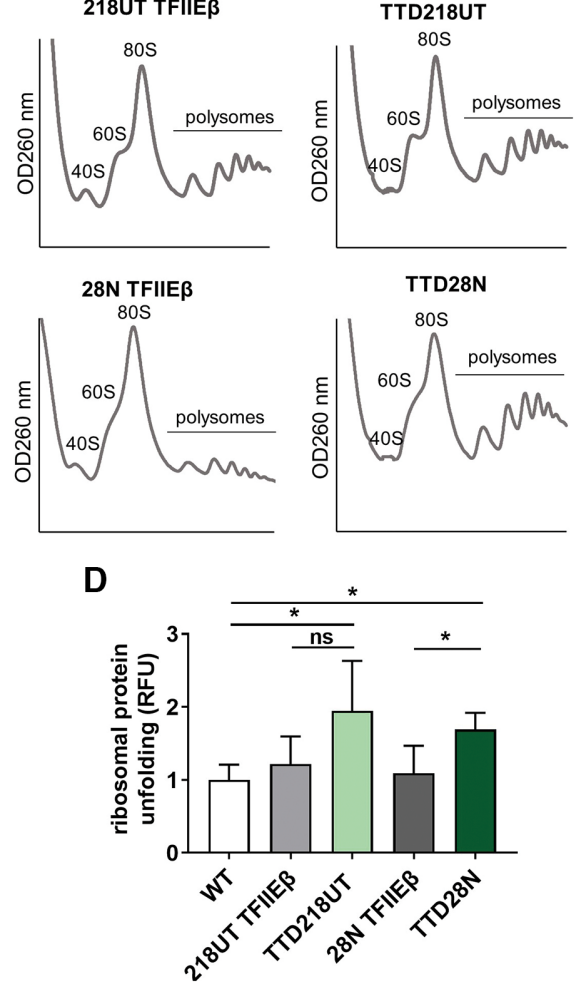

Figure 4. Mutation in TFIIE disturbs ribosomal composition and performance. (A) Left: Mass spectrometry analysis shows a non-significant decreased amount of ribosomal protein of the small 40S ribosome subunit and a non-significant increased amount of ribosome protein of the large $60 \mathrm{~S}$ ribosome subunit in TTD cells compared to reconstituted cells. Ribosomal proteins are color-coded with low detection (red), normal detection (white) and high detection (blue). A volcano plot is given in the Supplement S6C. Right: Western blot analysis of whole cell lysate and isolated ribosomes in all cells showing normal level of ribosomal proteins in lysate, but decreased level of RPS15 and increased level of RPL5 in isolated ribosomes of TTD cells. More western blot analyses of more ribosomal proteins and quantification are given in the Supplement S6D and E. (B) Fluorescence in situ hybridization with ITS1 Cy3-labeled probe indicates 18S-E accumulation in the nucleus and nucleolus in TTD cells compared to reconstituted and healthy controls. U2 C5labeled probe was used as control and indicates no significant differences in TTD cells (Supplement S6F). Quantification of the CTCF was performed as described in materials and methods. Measures were performed in at least 100 cells. (C) Polysome analysis shows a strong reduction of free 40S subunits in TTD cells compared to reconstituted and healthy controls. Insert: Quantification of area under the curve (AUC) of 40S peaks in WT, reconstituted and TTD cells indicating reduced AUC of 40S subunit in TTD cells. (D) Isolated ribosomes of WT, reconstituted and TTD cells were treated with 2M urea for 2 hrs. Exposed hydrophobic chains of unfolded proteins were quantified by Bis-ANS fluorescence. TTD cells show a higher amount of unfolded ribosomal proteins after partial denaturation. Data are represented as mean $\pm \mathrm{SD}$ of at least three independent experiments. ns $P>0.05, * P \leq 0.05, * * * P \leq 0.001$, **** $P \leq 0.0001$.

by analyzing $O$-propargylpuromycin (OPP) incorporation in the growing amino acid chain, which leads to a premature stop of translation. Interestingly, OPP incorporation revealed an increased translational initiation in TTD cells (Figure 5C). Strikingly, the overall protein synthesis, which was assessed by metabolic labeling, was found to be significantly reduced in TTD cells. (Figure 5D). These data suggest that increased ribosomal inaccuracy leads to higher but ineffective protein synthesis initiation. This notion was further supported by the finding that the cytoplasmic proteome of TTD cells is prone to heat denaturation. As shown in Fig- ure $5 \mathrm{E}$, more proteins are pelleted during centrifugation after heat-treatment, indicating an elevated load of misfolded proteins in TTD. Protein degradation analysis by measuring $20 \mathrm{~S}$ proteasome activity revealed a markedly and significant reduction of the $20 \mathrm{~S}$ proteasome activity in TTD cells (Figure $5 \mathrm{~F}$ ) that is in line with reduced overall protein synthesis. Finally, we speculate that disturbed protein homeostasis might also impact on cellular proliferation and compared growth properties of TTD cells with that of WT and reconstituted cells (Figure 5G). In comparison to WT cells, proliferation kinetics of TTD cells clearly revealed a reduced 
A
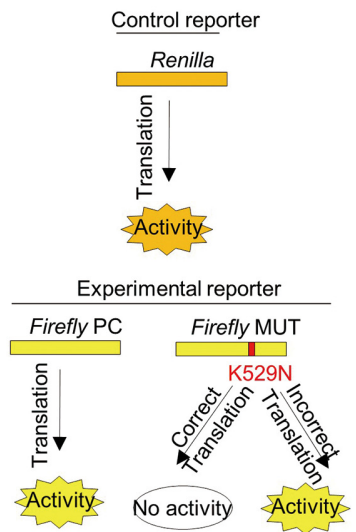

C
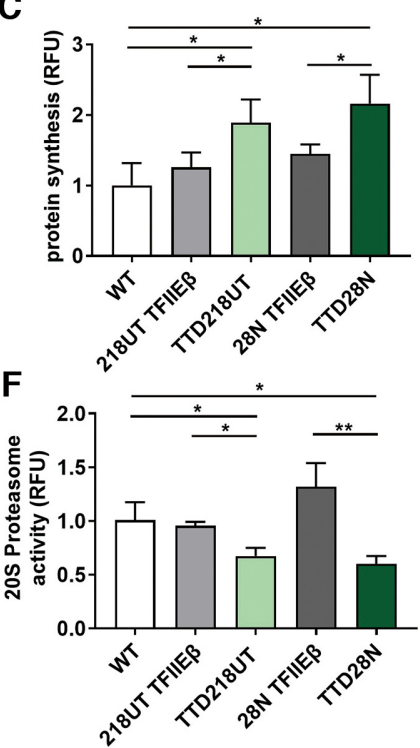

B plasmid transfection
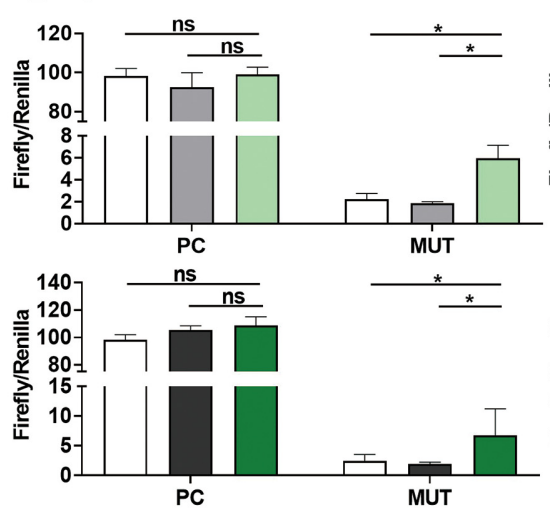

D

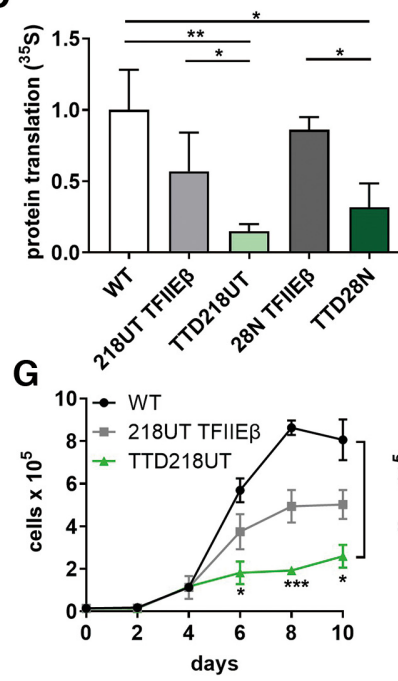

mRNA transfection

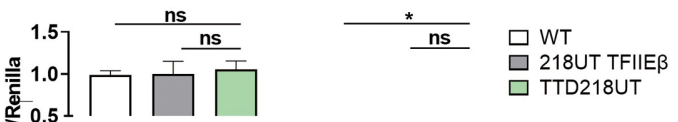

E

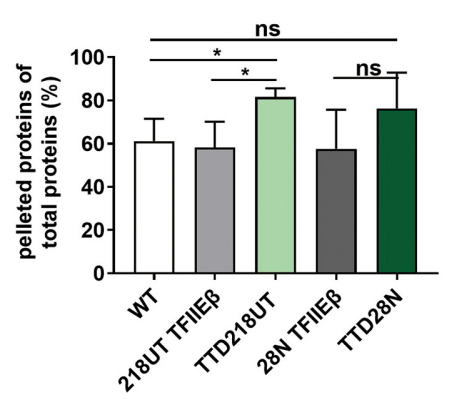

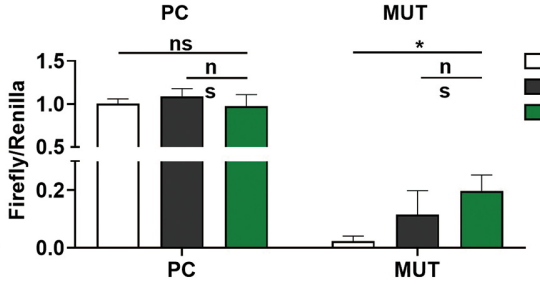

WT

28N TFIIE $\beta$

TTD28N

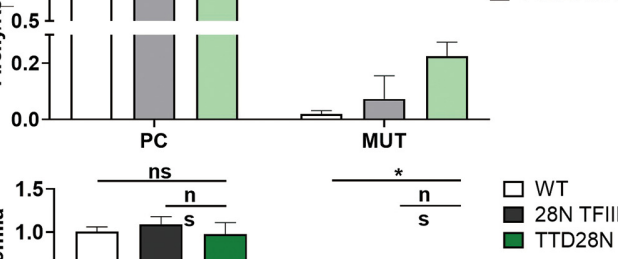

盛 0.5

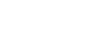

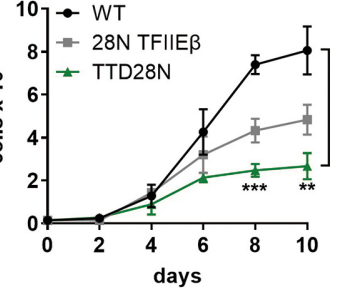

Figure 5. Loss of protein homeostasis in TTD cells. (A) Luciferase-based translation fidelity assay includes a control reporter Renilla and two Firefly reporters containing either no mutation (PC) or a point mutation K529N inactivating the Firefly (MUT). With correct translation, the point mutation is translated and Firefly is inactive, whereas with inaccurate translation the luminescence of the active Firefly is detected. The Firefly luminescence was normalized to the Renilla luminescence. (B) Left: To all cells, plasmids coding for Renilla were co-transfected via electroporation with either plasmids coding for Firefly NC or Firefly MUT. Translation fidelity assay with plasmids shows increased translational infidelity in TTD cells. Right: Plasmids coding for Renilla/Firefly PC or Renilla/Firefly MUT were transcribed by T7 polymerase and resulting mRNAs were transfected with lipofectamine to all cells. Translation fidelity assay with mRNAs indicates increased translational infidelity in TTD cells. (C) 5 FAM-Azide detection of OPP-labeled proteins indicates the rate of protein synthesis initiation in WT, reconstituted and TTD cells. TTD cells show increased translation initiation. (D) Analysis of total protein translation by using ${ }^{35} \mathrm{~S}$ metabolic labeling shows decreased protein synthesis in TTD cells compared to WT and reconstituted cells. (E) Heat sensitivity analysis of cytoplasmic extract in WT, reconstituted and TTD cells show increased percentage of pelleted proteins in TTD cells after heat treatment for $15 \mathrm{~min}$ at $99^{\circ} \mathrm{C}$. (F) Detection of cleaved 20S specific substrate, SUC-LLVY-AMC, indicating the 20S proteasome activity in WT, reconstituted and TTD cells. Reduced proteasome activity was observed in TTD cells. (G) Proliferation kinetics of TTD cells compared to WT and reconstituted cells indicate reduced cell proliferation in TTD cells. Data are represented as mean $\pm \mathrm{SD}$ of at least three independent experiments. ns $P>0.05, * P \leq 0.05, * *$ $P \leq 0.01, * * * P \leq 0.001$.

division rate in TTD cells when WT cells are in the exponential proliferation phase. Taken together, our data describe a severe disturbance in proteostasis as a novel pathomechanism which explains the observed reduced growth and proliferation rates in TTD cells, and which is most likely also responsible for the symptoms and clinical picture in TTD patients.

\section{DISCUSSION}

The heterodimeric general transcription factor TFIIE recruits TFIIH to the preinitiation complex of RNA poly- merase II promoters and is thus involved in gene expression of all protein-coding genes $(14,30)$. Here we describe an unanticipated role of TFIIE which profoundly impairs ribosomal biogenesis. Our data shows enrichment of TFIIE in the nucleolus, at the site of RNA polymerase I transcription. TFIIE enrichment depends on RNA polymerase I activity, as its inhibition by different compounds clearly reduces nucleolar TFIIE staining. So far, a nucleolar localization and function of general transcription factors of RNA polymerase II were reported for TFIIH $(10,31)$. A seminal publication indicates that nucleolar RNA polymerase II transcription is essential for proper rRNA biogenesis and 
processing (32). The authors showed that RNA polymerase II transcribes intergenic spacers (IGSs) of the rDNA to maintain nucleolar organization and hence rRNA synthesis and maturation. However, it is largely unresolved how RNA polymerase II transcribes at the IGSs of the rDNA, and which general factors are involved. We cannot exclude that the RNA polymerase II driven ribosomal protein expression is disturbed by mutant TFIIE and leads to a ribosomal assembly stress response as described in yeast (33). However, we here addressed the unique possibility that the nucleolar TFIIE enrichment is due to nucleolar RNA polymerase I transcription. In fact, our data unveil that the coding region of the rDNA, that is actively transcribed by RNA polymerase I, is bound by TFIIE and selective inhibition of RNA polymerase I transcription reduces TFIIE binding. These data highlight a direct involvement of TFIIE in RNA polymerase I transcription. The C-terminal end of TFIIE $\beta$ is capable of binding to DNA (34), suggesting that TFIIE may be bound to the rDNA through its small subunit TFIIE $\beta$. The fact that the mutation of TFIIE $\beta$ weakens the rDNA gene-occupancy of RNA polymerase I, indicates that TFIIE has a direct impact on the process of ribosomal biogenesis. Further investigations will reveal, if reduced binding of the elongation factor TFIIH to the rDNA is also observed, as TFIIE recruits TFIIH in RNA polymerase II pre-initiation complex formation (35). A reduced gene-occupancy of RNA polymerase I, as shown in this study, was already described by Nonnekens et al. (12) for TTD and CS-causing mutations in TFIIH and CSB indicating that this might be a common pathophysiology in these childhood syndromes. Moreover, in this publication, the authors further showed, that co-transcriptional processing of the pre-rRNA is disturbed in cells and tissues from a TTD mouse model with a mutation in TFIIH. The process of RNA polymerase I transcription elongation is coupled to the processing and pre-ribosomal assembly $(36,37)$, thus disturbances in transcription elongation might impact on the subsequent maturation steps. In our study, we demonstrate a previously unreported accumulation of processing intermediates and a reduced abundance of the $18 \mathrm{~S}$ mature rRNA in TFIIE $\beta$ mutant cells. Polysomal profiling revealed a reduced content of cytoplasmic 40S subunit in TFIIE $\beta$ mutant cells. Isolation of cytoplasmic ribosomes and mass spectrometric analysis also unraveled an underrepresentation of the 40S subunit in the cytoplasm. This is in line with the accumulation of unprocessed 18S-E intermediate in the nucleoplasm, presumably part of pre-40S particles, as identified by FISH. These results are confirmed by northern blot analysis showing a reduced mature $18 \mathrm{~S}$ in total cellular RNA. The knockdown of BMS1, an essential co-factor for rRNA processing is also leading to an underrepresentation of the 40S subunit in yeast (38). Maturation disturbances as a consequence of transcription elongation defects in the rRNA can also translate to ribosomal assembly defects as described in yeast (39). We compared ribosomal composition of patient cells with reconstituted cells and detected an underrepresentation of ribosomal proteins of the small ribosomal subunit. The small ribosomal subunit $40 \mathrm{~S}$ is the translation initiating and codon-decoding subunit of the ribosome. Disturbed ribosomal composition can lead to decoding defects of the ribosome (40-42) detectable by luciferase-based translation assays. We took advantage of a well-established luciferase transfection system (29) and discovered an elevated error rate of the translation process in TTD patient cells. The reduced translational fidelity, described for the first time in TTD, has recently been reported in CS-patient derived fibroblasts (17). We here found translational infidelity followed by a loss of proteostasis and disturbed protein synthesis in TTD, indicating that TTD and CS share distinct aspects in their pathophysiology and this may be a more general mechanism in both childhood syndromes. In this regard, both are caused by mutations in the same subunits of the transcription/DNA repair factor TFIIH. Additionally, these similarities might suggest, that the loss of proteostasis in CS might not origin from DNA damage, as a comparable defect is here shown for TTD cells which do not have any deficiencies in Nucleotide Excision Repair (13).

The loss of proteostasis is also evident by the elevation of heat-sensitive proteins in patient cells. Heat-stability of the proteome is a hallmark of long-living species and characterizes the longest-living animal, Arctica islandica (27). Elevated heat sensitivity indicates that a detectable proportion of the proteome is affected by misfolding, and this most likely is caused by translational errors. In support of this, ribosomal proteins display an elevated unfolding by urea in comparison to control ribosomes, indicating that the ribosomes themselves are affected by misfolded proteins likely due to an error-prone translation process. Our findings revitalize the error catastrophe theory of aging (43). In his theory, Orgel postulates that elevated translational infidelity perpetuates and enhances itself by the accumulation of errors in the amino acid sequence of ribosomal proteins that have an influence on translational fidelity.

The reduced translational fidelity at the ribosome in TFIIE $\beta$ mutant cells might be the cause of the observed loss of proteostasis. Interestingly, we detected an increase in the initiation of protein synthesis in TTD cells, while total protein synthesis is significantly reduced. This supports the assumption that the translation process is inefficient and error-prone in TFIIE $\beta$ cells. TTD is mainly regarded as a transcriptional syndrome, as $50 \%$ of the cases do not display DNA-repair disturbances (44). We here extend this classification and highlight a possible contribution of protein translation disturbances in the pathophysiology of TTD. Recently, mutations in aminoacyl-tRNA synthetases were identified to cause $\operatorname{TTD}(15,16)$ implying that a disturbed translation process, as shown in this study, might be causal for the developmental delay and neurodegeneration observed in TTD. This assumption is based on the hypothesis that only disturbances in a common cellular signaling pathway that is affected by all genes in this genotypical heterogenous disease can explain the phenotype. Here we provide first evidence, that the translation process at the ribosomes might be this common pathway. If also mutations in the TTD-causing genes TTDN1 (MPLKIP) and RNF113A are impacting the translation process awaits further analysis. 


\section{DATA AVAILABILITY}

All unique/stable reagents generated in this study are available from the Lead Contact with a completed Materials Transfer Agreement. Proteomics raw data, MaxQuant search results and the used protein sequence database have been deposited with the ProteomeXchange Consortium via the PRIDE partner repository (https://www.ebi.ac.uk/ pride/) and can be accessed using the data set identifier PXD023451.

\section{SUPPLEMENTARY DATA}

Supplementary Data are available at NAR Online.

\section{ACKNOWLEDGEMENTS}

We thank Arjan Theil and Wim Vermeulen from the Department of Molecular Genetics, Oncode Institute, Erasmus University Medical Center, University Medical Center Rotterdam (Netherlands) for providing the cell line TTD218UT and the plasmid pLenti_puro_CMV_TFIIE $\beta$ GFP; Donata Orioli from the Institute of Molecular Genetics, National Research Council Pavia (Italy) for providing the cell line TTD28N; Sabine Meessen from the Department of Urology, Ulm University (Germany) for providing the cell line BJ NH-TERT; Markus Schosserer from the Institute for Molecular Biotechnology, University of Natural Resources and Life Sciences Vienna (Austria) and Vera Gorbunova from the Department of Biology, University of Rochester (USA, NY) for providing Firefly and Renilla plasmid constructs for the luciferase-based translation fidelity assay. We used the confocal microscope and ultracentrifuge in the Institute of Molecular Genetics and Cell Biology, Ulm University (Germany) and thank Nils Johnsson, Thomas Gronemeyer and Matthias Hecht for permission and support. We are grateful Harsh Ranawat from the Institute for Biophysics, Ulm University (Germany) for providing antibodies and reagents for immunofluorescence, taking high resolution STED images and scientific discussion. We used the Compact Fluorescence Microscope KEYENCE in the Institute for Physiological Chemistry, University Ulm (Germany) and thank Thomas Wirth for permission and support. We further thank Lisa Wiesmüller from the Department of Gynecological Oncology, University Hospital Ulm (Germany), Ambra Giglia-Mari from the Institute for Neuromyogene, University Claude Bernhard Lyon 1 (France), Meinhard Wlaschek for scientific discussion and input.

Author contributions: Conceptualization, S.I.; Methodology, S.I., T.P. and P.M.; Investigation, T.P., L.S., C.L. and M.T.; Writing - Original Draft, T.P. and S.I.; Writing Review and Editing, S.I.; Visualization, T.P., M.T.; Funding Acquisition, S.I. and K.S.-K.; Resources, S.I., J.M. and K.S.-K.; Supervision; S.I., P.M., J.M., K.S.-K.

\section{FUNDING}

German Research Foundation (DFG) [IB83/3-4 to S.I.]; DFG program CEMMA (cellular and molecular mechanisms of aging) [GRK1789 to T.P.). Funding for open access charge: DFG, CEMMA [GRK1789].
Conflict of interest statement. None declared.

\section{REFERENCES}

1. Bassler,J. and Hurt,E. (2019) Eukaryotic ribosome assembly. Annu. Rev. Biochem., 88, 281-306.

2. Warner,J.R. (1999) The economics of ribosome biosynthesis in yeast. Trends Biochem. Sci., 24, 437-440.

3. Lewis,J.D. and Tollervey,D. (2000) Like attracts like: getting RNA processing together in the nucleus. Science, 288, 1385-1389.

4. Roeder,R.G. and Rutter,W.J. (1969) Multiple forms of DNA-dependent RNA polymerase in eukaryotic organisms. Nature, 224, 234-237.

5. Vannini,A. and Cramer,P. (2012) Conservation between the RNA polymerase I, II, and III transcription initiation machineries. Mol Cell, 45, 439-446.

6. Zhang,Y., Najmi,S.M. and Schneider,D.A. (2017) Transcription factors that influence RNA polymerases I and II: To what extent is mechanism of action conserved? Biochim. Biophys. Acta Gene Regul. Mech., 1860, 246-255.

7. Schultz,M.C., Reeder,R.H. and Hahn,S. (1992) Variants of the TATA-binding protein can distinguish subsets of RNA polymerase I, II, and III promoters. Cell, 69, 697-702.

8. Cormack,B.P. and Struhl,K. (1992) The TATA-binding protein is required for transcription by all three nuclear RNA polymerases in yeast cells. Cell, 69, 685-696.

9. Rimel,J.K. and Taatjes,D.J. (2018) The essential and multifunctional TFIIH complex. Protein Sci., 27, 1018-1037.

10. Iben,S., Tschochner,H., Bier,M., Hoogstraten,D., Hozak,P., Egly,J.M. and Grummt,I. (2002) TFIIH plays an essential role in RNA polymerase I transcription. Cell, 109, 297-306.

11. Assfalg,R., Lebedev,A., Gonzalez,O.G., Schelling,A., Koch,S. and Iben,S. (2012) TFIIH is an elongation factor of RNA polymerase I. Nucleic Acids Res., 40, 650-659.

12. Nonnekens,J., Perez-Fernandez,J., Theil,A.F., Gadal,O., Bonnart,C. and Giglia-Mari,G. (2013) Mutations in TFIIH causing trichothiodystrophy are responsible for defects in ribosomal RNA production and processing. Hum. Mol. Genet., 22, 2881-2893.

13. Theil,A.F., Mandemaker,I.K., van den Akker,E., Swagemakers,S.M.A., Raams,A., Wust,T., Marteijn,J.A., Giltay,J.C., Colombijn,R.M., Moog,U. et al. (2017) Trichothiodystrophy causative TFIIEbeta mutation affects transcription in highly differentiated tissue. Hum. Mol. Genet., 26, 4689-4698.

14. Compe,E., Genes,C.M., Braun,C., Coin,F. and Egly,J.M. (2019) TFIIE orchestrates the recruitment of the TFIIH kinase module at promoter before release during transcription. Nat. Commun., 10, 2084.

15. Theil,A.F., Botta,E., Raams,A., Smith,D.E.C., Mendes,M.I., Caligiuri,G., Giachetti,S., Bione,S., Carriero,R., Liberi,G. et al. (2019) Bi-allelic TARS mutations are associated with brittle hair phenotype. Am. J. Hum. Genet., 105, 434-440.

16. Kuo,M.E., Theil,A.F., Kievit,A., Malicdan,M.C., Introne,W.J., Christian,T., Verheijen,F.W., Smith,D.E.C., Mendes,M.I., Hussaarts-Odijk,L. et al. (2019) Cysteinyl-tRNA synthetase mutations cause a multi-system, recessive disease that includes microcephaly, developmental delay, and brittle hair and nails. Am. J. Hum. Genet., 104, 520-529.

17. Alupei,M.C., Maity,P., Esser,P.R., Krikki,I., Tuorto,F., Parlato,R., Penzo,M., Schelling,A., Laugel,V., Montanaro,L. et al. (2018) Loss of proteostasis is a pathomechanism in cockayne syndrome. Cell Rep., 23, 1612-1619.

18. Edvardson,S., Nicolae,C.M., Agrawal,P.B., Mignot,C., Payne,K., Prasad,A.N., Prasad,C., Sadler,L., Nava,C., Mullen,T.E. et al. (2017) Heterozygous de novo UBTF Gain-of-Function variant is associated with neurodegeneration in childhood. Am. J. Hum. Genet., 101, 267-273.

19. Sedlackova,L., Lassuthova,P., Sterbova,K., Haberlova,J., Vyhnalkova,E., Neupauerova,J., Stanek,D., Sediva,M., Krsek,P. and Seeman,P. (2019) UBTF mutation causes complex phenotype of neurodegeneration and severe epilepsy in childhood. Neuropediatrics, 50, 57-60.

20. Kara,B., Koroglu,C., Peltonen,K., Steinberg,R.C., Maras Genc,H., Holtta-Vuori,M., Guven,A., Kanerva,K., Kotil,T., Solakoglu,S. et al. 
(2017) Severe neurodegenerative disease in brothers with homozygous mutation in POLR1A. Eur. J. Hum. Genet., 25, 315-323.

21. Kuschal,C., Botta,E., Orioli,D., Digiovanna,J.J., Seneca,S., Keymolen,K., Tamura,D., Heller,E., Khan,S.G., Caligiuri,G. et al. (2016) GTF2E2 mutations destabilize the general transcription factor complex TFIIE in Individuals with DNA repair-proficient trichothiodystrophy. Am. J. Hum. Genet., 98, 627-642.

22. Grunberg,S., Warfield,L. and Hahn,S. (2012) Architecture of the RNA polymerase II preinitiation complex and mechanism of ATP-dependent promoter opening. Nat. Struct. Mol. Biol., 19, 788-796.

23. Osseforth,C., Moffitt,J.R., Schermelleh,L. and Michaelis,J. (2014) Simultaneous dual-color 3D STED microscopy. Opt. Express, 22, 7028-7039.

24. Wang,M. and Pestov,D.G. (2016) Quantitative northern blot analysis of mammalian rRNA Processing. Methods Mol. Biol., 1455, 147-157.

25. Penzo,M., Carnicelli,D., Montanaro,L. and Brigotti,M. (2016) A reconstituted cell-free assay for the evaluation of the intrinsic activity of purified human ribosomes. Nat. Protoc., 11, 1309-1325.

26. Rouquette,J., Choesmel,V. and Gleizes,P.E. (2005) Nuclear export and cytoplasmic processing of precursors to the $40 \mathrm{~S}$ ribosomal subunits in mammalian cells. EMBO J., 24, 2862-2872.

27. Treaster,S.B., Ridgway,I.D., Richardson,C.A., Gaspar,M.B., Chaudhuri,A.R. and Austad,S.N. (2014) Superior proteome stability in the longest lived animal. Age (Dordr), 36, 9597.

28. Perez,V.I., Buffenstein,R., Masamsetti,V., Leonard,S., Salmon,A.B., Mele,J., Andziak,B., Yang,T., Edrey,Y., Friguet,B. et al. (2009) Protein stability and resistance to oxidative stress are determinants of longevity in the longest-living rodent, the naked mole-rat. Proc. Natl. Acad. Sci. U.S. A., 106, 3059-3064.

29. Azpurua,J., Ke,Z., Chen,I.X., Zhang,Q., Ermolenko,D.N. Zhang,Z.D., Gorbunova,V. and Seluanov,A. (2013) Naked mole-rat has increased translational fidelity compared with the mouse, as well as a unique $28 \mathrm{~S}$ ribosomal RNA cleavage. Proc. Natl. Acad. Sci. U.S.A., 110, 17350-17355.

30. Ohkuma,Y., Sumimoto,H., Horikoshi,M. and Roeder,R.G. (1990) Factors involved in specific transcription by mammalian RNA polymerase II: purification and characterization of general transcription factor TFIIE. Proc. Natl. Acad. Sci. U.S.A., 87, 9163-9167.

31. Hoogstraten,D., Nigg,A.L., Heath,H., Mullenders,L.H., van Driel,R., Hoeijmakers,J.H., Vermeulen,W. and Houtsmuller,A.B. (2002) Rapid switching of TFIIH between RNA polymerase I and II transcription and DNA repair in vivo. Mol. Cell, 10, 1163-1174.

32. Abraham,K.J., Khosraviani,N., Chan,J.N.Y., Gorthi,A., Samman,A., Zhao,D.Y., Wang,M., Bokros,M., Vidya,E., Ostrowski,L.A. et al.
(2020) Nucleolar RNA polymerase II drives ribosome biogenesis. Nature, 585, 298-302.

33. Albert,B., Kos-Braun,I.C., Henras,A.K., Dez,C., Rueda,M.P., Zhang,X., Gadal,O., Kos,M. and Shore,D. (2019) A ribosome assembly stress response regulates transcription to maintain proteome homeostasis. Elife, 8 , e45002.

34. Okamoto,T., Yamamoto,S., Watanabe,Y., Ohta,T., Hanaoka,F., Roeder,R.G. and Ohkuma,Y. (1998) Analysis of the role of TFIIE in transcriptional regulation through structure-function studies of the TFIIEbeta subunit. J. Biol. Chem., 273, 19866-19876.

35. Roeder,R.G. (1996) The role of general initiation factors in transcription by RNA polymerase II. Trends Biochem. Sci., 21, 327-335.

36. Scull,C.E. and Schneider,D.A. (2019) Coordinated control of rRNA processing by RNA polymerase I. Trends Genet., 35, 724-733.

37. Bohnsack,K.E. and Bohnsack,M.T. (2019) Uncovering the assembly pathway of human ribosomes and its emerging links to disease. EMBO J., 38, e100278

38. Wegierski,T., Billy,E., Nasr,F. and Filipowicz,W. (2001) Bms1p, a G-domain-containing protein, associates with Rcllp and is required for 18S rRNA biogenesis in yeast. RNA, 7, 1254-1267.

39. Schneider,D.A., Michel,A., Sikes,M.L., Vu,L., Dodd,J.A., Salgia,S. Osheim,Y.N., Beyer,A.L. and Nomura,M. (2007) Transcription elongation by RNA polymerase I is linked to efficient rRNA processing and ribosome assembly. Mol. Cell, 26, 217-229.

40. Paolini,N.A., Attwood,M., Sondalle,S.B., Vieira,C., van Adrichem,A.M., di Summa,F.M., O'Donohue,M.F., Gleizes,P.E., Rachuri,S., Briggs,J.W. et al. (2017) A ribosomopathy reveals decoding defective ribosomes driving human dysmorphism. Am. J. Hum. Genet., 100, 506-522.

41. Lezzerini,M., Penzo,M., O’Donohue,M.F., Marques Dos Santos Vieira,C., Saby,M., Elfrink,H.L., Diets,I.J., Hesse,A.M., Coute,Y., Gastou,M. et al. (2020) Ribosomal protein gene RPL9 variants can differentially impair ribosome function and cellular metabolism. Nucleic Acids Res. 48, 770-787.

42. Venturi,G. and Montanaro,L. (2020) How altered ribosome production can cause or contribute to human disease: the spectrum of ribosomopathies. Cells, 9, 2300.

43. Orgel,L.E. (1963) The maintenance of the accuracy of protein synthesis and its relevance to ageing. Proc. Natl. Acad. Sci. U.S.A., 49, 517-521.

44. Stefanini,M., Botta,E., Lanzafame,M. and Orioli,D. (2010) Trichothiodystrophy: from basic mechanisms to clinical implications. DNA Repair (Amst.), 9, 2-10.

45. Mullineux,S.T. and Lafontaine,D.L. (2012) Mapping the cleavage sites on mammalian pre-rRNAs: where do we stand? Biochimie, 94, $1521-1532$. 